\title{
Pallidal Deep-Brain Stimulation Disrupts Pallidal Beta Oscillations and Coherence with Primary Motor Cortex in Parkinson's Disease
}

\author{
DDoris D. Wang, ${ }^{1}$ Coralie de Hemptinne, ${ }^{1}$ Svjetlana Miocinovic, ${ }^{3}$ Jill L. Ostrem, ${ }^{2}$ Nicholas B. Galifianakis, ${ }^{2}$ \\ Marta San Luciano, ${ }^{2}$ and $\odot$ Philip A. Starr ${ }^{1}$ \\ Departments of ${ }^{1}$ Neurological Surgery, ${ }^{2}$ Neurology, University of California San Francisco, San Francisco, California 94143-0112, and ${ }^{3}$ Department of \\ Neurology, Emory University School of Medicine, Atlanta, Georgia 30322
}

In Parkinson's disease (PD), subthalamic nucleus beta band oscillations are decreased by therapeutic deep-brain stimulation (DBS) and this has been proposed as important to the mechanism of therapy. The globus pallidus is a common alternative target for PD with similar motor benefits as subthalamic DBS, but effects of pallidal stimulation in PD are not well studied, and effects of pallidal DBS on cortical function in PD are unknown. Here, in 20 PD and 14 isolated dystonia human patients of both genders undergoing pallidal DBS lead implantation, we recorded local field potentials from the globus pallidus and in a subset of these, recorded simultaneous sensorimotor cortex ECoG potentials. PD patients had elevated resting pallidal low beta band (13-20 Hz) power compared with dystonia patients, whereas dystonia patients had elevated resting pallidal theta band $(4-8 \mathrm{~Hz})$ power compared with PD. We show that this results in disease-specific patterns of interaction between the pallidum and motor cortex: PD patients demonstrated relatively elevated phase coherence with the motor cortex in the beta band and this was reduced by therapeutic pallidal DBS. Dystonia patients had greater theta band phase coherence. Our results support the hypothesis that specific motor phenomenology observed in movement disorders are associated with elevated network oscillations in specific frequency bands, and that DBS in movement disorders acts in general by disrupting elevated synchronization between basal ganglia output and motor cortex.

Key words: basal ganglia thalamocortical network; beta oscillations; dystonia; electrocorticography; local field potential; synchronization

Significance Statement

Perturbations in synchronized oscillatory activity in brain networks are increasingly recognized as important features in movement disorders. The globus pallidus is a commonly used target for deep-brain stimulation (DBS) in Parkinson's disease (PD), however, the effects of pallidal DBS on basal ganglia and cortical oscillations are unknown. Using invasive intraoperative recordings in patients with PD and isolated dystonia, we found disease-specific patterns of elevated oscillatory synchronization within the pallidum and in coherence between pallidum and motor cortex. Therapeutic pallidal DBS in PD suppresses these elevated synchronizations, reducing the influence of diseased basal ganglia on cortical physiology. We propose a general mechanism for DBS therapy in movement disorders: functional disconnection of basal ganglia output and motor cortex by coherence suppression.

\section{Introduction}

Alterations in synchronized oscillatory activity in brain networks are increasingly recognized as important in neurological disease

Received Feb. 16, 2018; revised March 27, 2018; accepted April 5, 2018.

Author contributions: D.D.W. wrote the first draft of the paper; D.D.W., C.d.H., J.L.O., N.B.G., M.S.L., and P.A.S. edited the paper; D.D.W. and P.A.S. designed research; D.D.W. and C.d.H. performed research; D.D.W., C.d.H., and S.M. contributed unpublished reagents/analytic tools; D.D.W. analyzed data; D.D.W. and P.A.S. wrote the paper. This work was supported by NIH R25 PAR-13-384 NINDS Grant and R01 NS090913-01.

The authors declare no competing financial interests.

Correspondence should be addressed to Dr. Doris D. Wang, Department of Neurological Surgery, University of California San Francisco, 505 Parnassus Avenue, M779, Box 0112, San Francisco, CA 94143-0112. E-mail: doris.wang@ucsf.edu.
(Voytek and Knight, 2015). In movement disorders such as Parkinson's disease (PD), much has been learned about oscillatory activity from invasive recordings of field potentials in humans undergoing deep-brain stimulator (DBS) implantation surgery. In $\mathrm{PD}$, dopamine replacement and DBS therapy reduce the resting-state amplitude of beta band (13-30 Hz) oscillatory activity in the subthalamic nucleus (STN), and these reductions correlate with improvements in bradykinesia and rigidity (Brown et al., 2001; Priori et al., 2004; Kühn et al., 2008; Bronte-Stewart et 
al., 2009). Furthermore, dopamine replacement and STN DBS both reduce cortical synchronization, as manifested by the entrainment of high-frequency activity to beta phase (de Hemptinne et al., 2015; Swann et al., 2015). These findings support the theory that excessive beta oscillatory synchronization throughout the basal ganglia-thalamocortical (BGTC) motor circuit is a key component of the circuit abnormality underlying the motor signs of PD (Weinberger et al., 2006; Hammond et al., 2007; Giannicola et al., 2010; Oswal et al., 2013).

Most invasive studies of human physiology in PD have focused on the STN alone or on subthalamic-cortical interactions. However, there is increasing interest in targeting the globus pallidus (GP) for DBS therapy in PD, based on equivalent motor benefits in three of four randomized trials of STN versus GP DBS (Anderson et al., 2005; Okun et al., 2009; Follett et al., 2010; Odekerken et al., 2013; Ramirez-Zamora and Ostrem, 2018) and increased safety in patients with pre-existing mild cognitive decline or mood disorders (Okun et al., 2009; Follett et al., 2010). Consistent with the evolving theory of excessive beta oscillatory activity in $\mathrm{PD}$, several studies have shown higher resting-state beta band oscillatory activity in the GP of PD compared with non-parkinsonian conditions (Silberstein et al., 2003; Weinberger et al., 2012; Jimenez-Shahed et al., 2016). However, no studies have investigated interactions between the pallidum and the sensorimotor cortex in PD at high spatial and temporal resolution, compared such interaction with non-PD conditions, or studied the network effects of therapeutic pallidal DBS.

Here, using combined local field potential (LFP) and electrocorticography (ECoG) recordings in patients undergoing DBS in the awake state, we evaluate pallidal and cortical oscillatory activity in akinetic-rigid PD and in a nonparkinsonian disorder, isolated dystonia. We confirm in this large series that PD patients have relatively elevated resting pallidal oscillatory synchronization in the beta range, whereas dystonia patients have relatively higher theta oscillations (Silberstein et al., 2003; Weinberger et al., 2012). We show that these patterns of oscillatory synchronization in basal ganglia output influence primary motor cortex through disease-specific patterns of phase coherence, and that therapeutic pallidal stimulation disrupts elevated pallido-cortical beta coherence in PD. We propose that this disruption of synchronization between basal ganglia output and motor cortex represents a general mechanism for the therapeutic effect of basal ganglia DBS in movement disorders.

\section{Materials and Methods}

\section{Patients}

Patients with PD and isolated dystonia were recruited from the movement disorders surgery clinics at the University of California San Francisco or the San Francisco Veteran Affairs Medical Center. Our study included $20 \mathrm{PD}$ patients (18 male, 2 female) and 14 isolated dystonia patients ( 8 male, 6 female). All patients were scheduled to undergo implantation of DBS electrodes into the GP, and underwent evaluation for motor impairments within 3 months before surgery using the Unified Parkinson's Disease Rating Scale motor subscale (UPDRS-III) in the offand on-medication states (for PD patients), or the Toronto Western Spasmodic Torticollis Rating Scale and Burke-Fahn-Marsden Dystonia Rating Scale (for dystonia patients). Preoperative levodopa equivalent dose was reported for PD patients (Wenzelburger et al., 2002). Inclusion criteria were the following: for PD patients, akinesia and rigidity as the most prominent symptoms with UPDRS-III $\geq 30$ in the off state and absent observed tremor during the resting-state intraoperative recording, since tremor can have a confounding effect on beta band activity (Qasim et al., 2016). Note that PD Patient 14 only had tremors during the DBS ON/OFF recordings and not during resting-state recordings. Significant tremor was detected based on an accelerometer attached to the contralateral wrist, rhythmic EMG activity, and/or review of the intraoperative video. For isolated dystonia patients, those with focal cervical dystonia, segmental craniocervical dystonia or generalized dystonia without evidence for acquired etiology were included in the study. Informed consent was obtained before surgery under a protocol approved by the Institutional Review Board.

\section{DBS electrode implantation in PD and dystonia patients}

Surgery and recording was performed at least $12 \mathrm{~h}$ after stopping all dopaminergic medications (PD group), and oral benzodiazepines and baclofen (dystonia group). Surgical planning and placement of DBS electrodes in the GP were performed using methods previously described (Starr, 2002). Briefly, the intended target location in the posterior internal pallidum is identified on T2 or inversion-recovery (IR) fast spin echo sequence, $\sim 17.5 \mathrm{~mm}$ lateral to the wall of the third ventricle, $2 \mathrm{~mm}$ anterior, and $5 \mathrm{~mm}$ inferior to the mid commissural point (the midpoint of the line connecting the anterior and posterior commissures; Fig. 1A). All surgeries were performed in the awake resting state after discontinuation of propofol for at least $30 \mathrm{~min}$. Microelectrode recordings (MERs) were performed to map movement-related single units, and borders of the GPi and GPe were defined based on the MER map. A DBS lead (Medtronic model 3387 for all patients) was then placed. All DBS electrodes were placed with Contact 0 at the base of GP, at the border with optic tract, Contact 1 in the GPi, and Contacts 2 and/or 3 in the GPe. LFPs were recorded from the motor territory in the bipolar configuration with Contact 1 as the active electrode and either Contact 0 or 2 as reference. Targeting was confirmed by electrical stimulation-induced symptom improvement and side effect thresholds obtained by DBS stimulation. Postoperative MRI was used to confirm correct lead location.

\section{Subdural electrode placement and localization}

LFPs were recorded in all patients. In addition, a subset of patients underwent placement of a temporary subdural electrode to record signals from the motor cortex (13 PD patients and 12 dystonia patients). A 6-contact subdural ECoG strip (all except PD Patients 18 and 20, who had a high-density 28-contact ECoG strip) was placed on the surface of the brain through the same burr hole used for the DBS implantation. Signals recorded using the 6-contact ECoG electrodes (11 PD patients, 12 dystonia patients) were used for all M1 spectral power and coherence comparisons across PD and dystonia patients to keep our methodology consistent. Data collected from the 28-contact ECoG electrode were only used for within-subject comparisons during DBS OFF/ON/OFF experiments for PD patients (see next section).

The intended target location was the arm area of primary motor cortex (M1), $\sim 3 \mathrm{~cm}$ from the midline and slightly medial to the hand knob (Fig. $1 B)$. The ECoG contact locations were confirmed anatomically using intraoperative computed tomography (iCT) fused to the preoperative planning magnetic resonance imaging with standard surgical planning software (Framelink v5.1, Medtronic). Median nerve somatosensoryevoked potentials (SSEPs) were recorded, and reversal of the first negative component of the cortical SSEP (N20) waveform indicated the M1 contact location (Fig. 1C; Crowell et al., 2012; de Hemptinne et al., 2013; Miocinovic et al., 2015). We found high concordance between anatomical and physiologic determinations of contact position with respect to the central sulcus (CS) in 20 of 25 patients, but in case of discrepancy (5 patients), the SSEP location was used. M1 spectral power and coherence analysis were performed using the signal recorded from contact pairs spanning M1 (as specified by SSEP reversal and anatomical localization).

\section{Intracranial recording}

All pallidal LFP recordings were performed intraoperatively within 5-30 min after DBS electrode implantation. The LFPs and ECoG potentials were recorded using the Alpha Omega Microguide Pro $(n=19 ; 9$ PD, 10 dystonia patients), the Neuro Omega (Alpha Omega; $n=12 ; 8 \mathrm{PD}, 4$ dystonia patients), or the PZ5 Neurodigitizer (Tucker-David Technologies; $n=3$ PD patients) and sampled at 3000; 22,000; or $3052 \mathrm{~Hz}$, respectively. Signals were high-pass filtered at $1 \mathrm{~Hz}$. Bipolar GP LFPs were recorded from the physiologically identified motor territory between either Contacts 1 (active) and 0 (reference) or Contacts 1 (active) and 2 (reference) of the DBS electrode. Because the electrode array spans both 
A

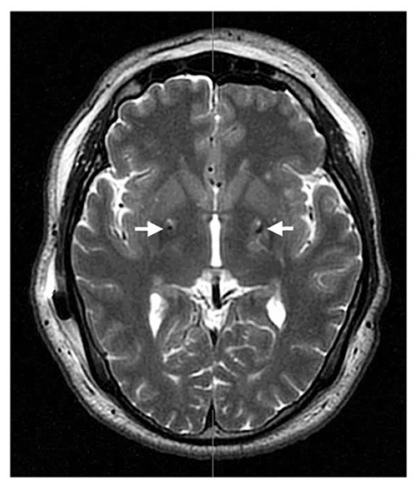

B

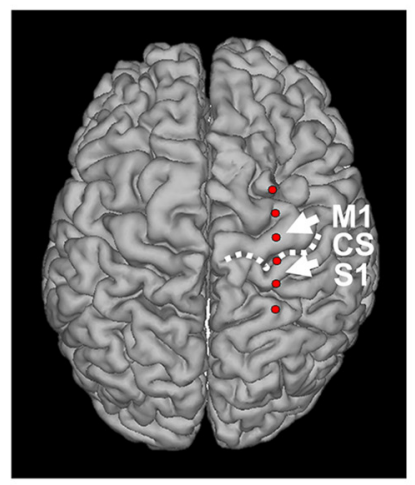

C

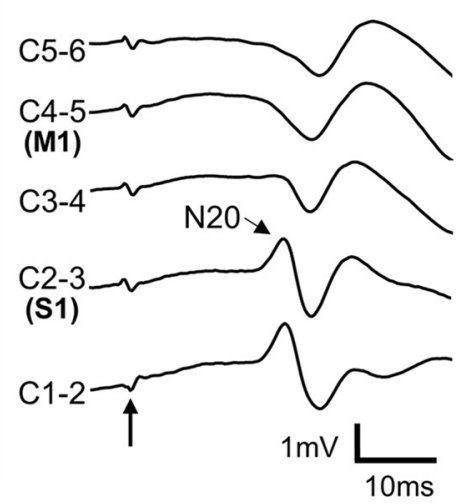

D

Pallidal LFP

\section{M1 ECoG potential}

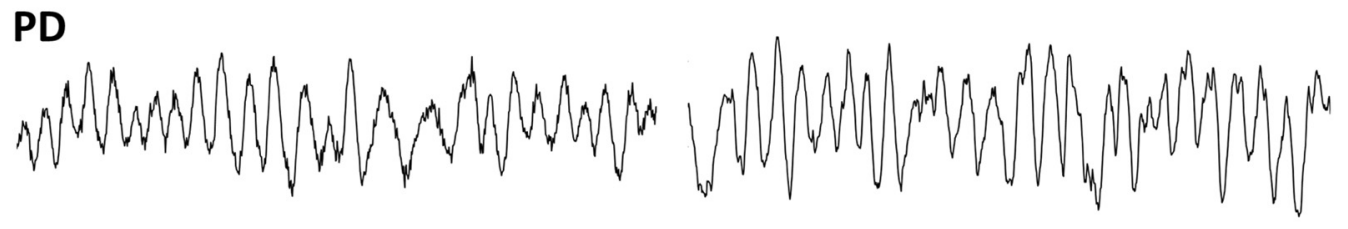

Dystonia

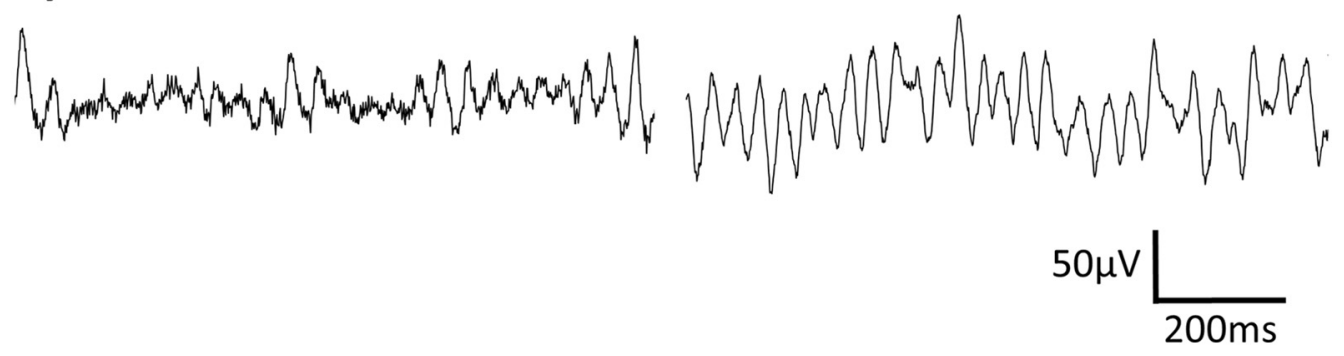

Figure 1. Pallidal lead and cortical electrode locations and field potential recordings. A, Axial T2-weighted MRI showing pallidal DBS lead locations in the anterior and posterior commissural (AC-PC) plane. Arrows indicate lead artifact. B, 3D-recontruction of preoperative MRI fused with intraoperative CT showing location of the temporary subdural 6-contact M1 EC OG strip in a PD patient. White dotted line indicates the CS. S1, Primary sensory cortex. C, Median nerve SSEP shows reversal of the N20 potential at the electrode contact pair spanning M1 (C4 -C5). Arrows indicate the time of stimulation, and downward direction is negative. The most posterior contact pair with a negative N2O waveform is the C4 - C5 pair, localizing Contact 4 to $\mathrm{M} 1$, which is immediately anterior to the central sulcus. D, One second sample resting-state pallidal LFP signals (left) and M1 ECoG signals recorded from a PD patient (top) and a dystonia patient (bottom).

the internal and external pallidum, we refer to the recording site using the more general term "globus pallidus" rather than "globus pallidus internus". All ECoG potentials were recorded in bipolar configuration with either the most anterior contact of a 6-contact electrode (Contact 6) used as reference (when using the Alpha Omega system) or a scalp needle as reference (when using the Neuro Omega and TDT systems). All recorded signals were then re-referenced off-line by subtracting signals from adjacent contacts (1-2, 2-3, etc) for the 6-contact ECoG strip (23 patients) or by subtracting the common average from all electrodes for the 28-contact strip electrodes (2 patients).

DBS stimulation. Four PD patients (Patients 3, 8, 18, and 20) underwent simultaneous recording of pallidal LFP and motor ECoG potential during therapeutic pallidal DBS stimulation through the DBS lead (monopolar stimulating using Contact 1 as the active electrode and shoulder pad as reference) using either the Neuro Omega (Patient 3: $130 \mathrm{~Hz}, 90$ $\mu \mathrm{S}, 2-4 \mathrm{~mA}$ ) or an analog neurostimulator (Medtronic, model 3625; Patients 8, 18, and 20: $180 \mathrm{~Hz}, 60-90 \mu \mathrm{S}, 4-6 \mathrm{~V})$. Pallidal LFP were recorded from Contacts 0 and 2. Changes in clinical symptoms were determined in contralateral limb rigidity, bradykinesia, and tremor using the UPDRS III motor subscale by an unblinded neurologist.

\section{Behavioral tasks}

Recordings were performed in two conditions. (1) During rest: patients were instructed to keep their eyes open and refrain from any voluntary movements. (2) During a movement task: patients performed flexionextension of the elbow (3-5 s movement epoch and 3-5 s hold epoch repeated for $1 \mathrm{~min}$; $5 \mathrm{PD}, 7$ dystonia patients) or an iPad (Apple) tapping task where the patient lifted his or her arm from the resting position and touched dots on the screen on cue ( $\sim 5 \mathrm{~s}$ of movement with $5 \mathrm{~s}$ of hold epoch repeated 10 times; 2 PD, 3 dystonia patients; de Hemptinne et al., 2015; Rowland et al., 2015). All patients had recordings performed at rest, and seven patients with PD and 10 patients with dystonia underwent the movement task. We distinguish "rest" from "hold" as patients were engaged in a task and prepared to move during the hold epochs. Muscle activity was recorded using surface electromyography from the deltoid, biceps brachii, and extensor carpi radialis muscles. Movement was detected by a wrist accelerometer.

\section{Signal processing and data analysis}

LFP and ECoG potential data were processed and analyzed offline in MATLAB (MathWorks). Data were down sampled to $1 \mathrm{kHz}$ and notch filtered for power line noise $(60 \mathrm{~Hz})$ and its harmonics (at 120, 180, 240 $\mathrm{Hz}$ ) using a Butterworth filter. For data recorded at rest, the first $30 \mathrm{~s}$ of data without obvious electrical noise or movement were selected for the analyses. For data recorded during DBS ON, stimulation artifact was rejected by removing 30 sample data points $(22,000 \mathrm{~Hz}$ sampling rate) around the stimulation artifact peak, and interpolating the data points at the beginning and end of artifact using a straight line (Patient 3). For 
Patients 8, 18, and 20, there was less high-frequency stimulation artifact such that notch filtering alone was sufficient for artifact removal. Data recorded during stimulation was notch-filtered for stimulation frequency $(130$ or $180 \mathrm{~Hz})$ and its first and second order harmonics using a Butterworth filter. For data recorded during the movement task, hold and movement epochs were defined using EMG data and each epoch $>1 \mathrm{~s}$ were included for power spectral density (PSD) analyses (see next section).

Spectral power. PSD was calculated using the Welch periodogram method (MATLAB function pwelch). For PSD calculations, we used a fast Fourier transform of 1024 points (for a frequency resolution of 0.95 $\mathrm{Hz}$ ) and $50 \%$ overlap using a Hann window to reduce edge effects. Power was normalized as percentage of total power between 4 and $100 \mathrm{~Hz}$ excluding 55-65 Hz line noise (Silberstein et al., 2003). Percentage total power of the resulting normalization was averaged across the following frequency bands: theta $(4-8 \mathrm{~Hz})$, alpha $(8-12 \mathrm{~Hz})$, low beta $(13-20 \mathrm{~Hz})$, high beta $(20-30 \mathrm{~Hz})$, beta $(13-30 \mathrm{~Hz})$, broadband gamma $(50-200 \mathrm{~Hz})$, and high-frequency oscillations (HFO; $200-400 \mathrm{~Hz}$ ).

Spectrograms during DBS OFF/ON/OFF recording were performed using the short time Fourier transform (MATLAB function spectrogram) with a 1024 point window and $50 \mathrm{~ms}$ frame advance. Spectral power across the entire recording is plotted on a log power color scale.

Beta burst. To quantify bursts of LFP or ECoG potential beta activity, we used methods previously described (Tinkhauser et al., 2017a,b). Beta band peaks were individually visually identified on log spectral power density plots. Each LFP or ECoG potential signal was bandpass filtered $( \pm 4 \mathrm{~Hz})$ around individual beta peak frequency, and the amplitude envelope of the beta activity envelope was obtained. A threshold was then set at the 75 th percentile of the beta amplitude. The onset of a burst was defined as when the filtered signal crossed the threshold amplitude and the end of the burst defined as when the amplitude fell below threshold (see Fig. $4 A$ ). An example of a scatter plot showing the distribution of burst amplitudes and lengths is demonstrated in Figure 4B. Bursts lasting $<100 \mathrm{~ms}$ were discarded from analysis. Bursts were then categorized according to their duration into nine time windows and compared across disease states. Mean amplitudes, mean durations of bursts, and burst frequencies (number of bursts per second) were calculated for each individual recording and compared across disease states.

Coherence. Coherence (magnitude-squared coherence) was calculated using Welch's averaged modified periodogram method with a $1 \mathrm{~s}$ window and a frequency resolution of $1 \mathrm{~Hz}$ (MATLAB function mscohere). Coherence was analyzed along a spectrum of frequencies, and averaged across the aforementioned frequency bands. Comparisons were made between averaged coherence in a given frequency band.

Phase coherence, was measured by bandpass filtering each signal around the frequency band of interest using a two-way, least-squares FIR filter (eegfilt from EEGLAB toolbox). Phase information was extracted from each filtered signal using the Hilbert transform, and was used to calculate the phase difference, $\phi_{\Delta}$. The angular phase difference distribution was obtained by transforming $\phi_{\Delta}$ onto the unit circle in the complex plane using Euler's formula (Qasim et al., 2016).

Amplitude coherence was performed by taking the amplitude envelope for each bandpass-filtered signal and calculating the Pearson's correlation coefficient between the amplitude envelopes over the course of recording. This correlation coefficient was squared to make it more comparable to magnitude-squared coherence (Qasim et al., 2016).

Phase-amplitude coupling. We calculated phase-amplitude coupling (PAC) between the phase of low frequencies $(4-50 \mathrm{~Hz})$ and the amplitude of high frequencies $(50-200 \mathrm{~Hz})$ from M1 ECoG potentials using the Tort method (Tort et al., 2010). Mean beta phase-gamma amplitude PAC value was calculated by averaging PAC indices from 13 to $30 \mathrm{~Hz}$ in the phase frequency range and from 50 to $200 \mathrm{~Hz}$ in the amplitude frequency range (de Hemptinne et al., 2015; Miocinovic et al., 2015).

\section{Statistical analysis}

The nonparametric Wilcoxon rank sum test (MATLAB function ranksum) was used to evaluate differences between PD and dystonia patients for all variables studied. Two-way ANOVA was used to compare beta burst distribution and disease state (Tinkhauser et al., 2017b). Repeated- measure ANOVA with post hoc Tukey's test was used for within-subject comparisons during different DBS stimulation conditions. All statistics with multiple comparisons were false discovery rate (FDR)-corrected and only adjusted $p$ values are presented (Hochberg and Benjamini, 1990).

\section{Results}

\section{Study subjects}

We recorded simultaneous pallidal and motor cortex recordings in $13 \mathrm{PD}$ patients and 12 dystonia patients. In an additional seven PD and one dystonia patients, we recorded only pallidal LFPs. Clinical characteristics, including lead contact locations, for PD and dystonia patients are summarized in Tables 1 and 2, respectively. Mean age was $63.3 \pm 7.7$ years for $\mathrm{PD}$ and $44.7 \pm 11.8$ years for dystonia. For PD patients, mean UPDRS-III off medication score $46 \pm 11$ and on medication was $24 \pm 8$. For dystonia patients, the mean TWSTRS score was $18 \pm 10$ and BFMDRS score was $19 \pm 12$. Seven of the dystonia patients had focal cervical or segmental craniocervical forms, without any limb or trunk involvement, and seven had generalized dystonia. Example lead location in the GP and cortex, and examples of resting recordings in $\mathrm{PD}$ and dystonia are shown in Figure 1.

\section{Pallidal, and not M1, beta and theta oscillations distinguish $\mathrm{PD}$ and dystonia in the resting state}

First, we used all pallidal recordings (pooling those with and without simultaneous cortical recordings) to confirm diseasespecific patterns of pallidal oscillatory activity. Representative GP LFP recordings for a PD and dystonia patient are shown in Figure $1 D$. Average LFP RMS voltage was $19.3 \pm 14.4 \mu \mathrm{V}$ for PD and $16.3 \pm 13.6 \mu \mathrm{V}$ for dystonia $(p=0.2554$; Wilcoxon rank sum test). Log-transformed PSDs for a PD patient and a dystonia patient are plotted in Figure $2 A$, and group comparisons showed that $\mathrm{PD}$ patients had higher resting beta power than dystonia $(\mathrm{PD}$ vs dystonia: low beta: $p=0.0039$, high beta: $p=0.0224$; post hoc FDR-adjusted Wilcoxon rank sum). To account for intersubject variability in signal amplitude, we normalized each power spectrum as percentage of total power between 4 and $100 \mathrm{~Hz}$ excluding line noise $\sim 55-65 \mathrm{~Hz}$ (Silberstein et al., 2003; Fig. 2C). Normalized spectral power was averaged for physiologically relevant frequency bands theta $(4-8 \mathrm{~Hz})$, alpha $(8-12 \mathrm{~Hz})$, low beta $(13-20 \mathrm{~Hz})$, high beta $(20-30 \mathrm{~Hz})$, broadband gamma $(50-200$ $\mathrm{Hz})$, and HFO $(200-400 \mathrm{~Hz})$. We found that dystonia patients had higher theta power than PD, and PD patients had higher low beta band power than dystonia (PD vs dystonia: theta: $p=$ 0.0223 , alpha: $p=1.0$, low beta: $p=0.0132$, high beta: $p=$ 0.7342 , broadband gamma: $p=0.1323$, HFO: $p=0.7342$; post hoc FDR-adjusted Wilcoxon rank sum; Fig. $2 C$ ).

We also compared resting oscillatory activity recorded from M1 in a subset of $11 \mathrm{PD}$ and 12 dystonia patients with a temporarily placed 6-contact ECoG strip electrode placed over the sensorimotor area (Fig. 1B). Representative M1 ECoG potentials and log spectral powers from a PD and dystonia patient are shown in Figures $1 D$ and $2 B$, respectively. Normalized M1 spectral power showed no difference in any oscillatory bands measured (PD vs dystonia: theta: $p=0.9755$, alpha: $p=0.6903$, low beta: $p=$ 0.9382 , high beta: $p=0.6903$, broadband gamma: $p=0.8834$, HFO: $p=0.9382$; post hoc FDR-adjusted Wilcoxon rank sum test; Fig. 2D).

\section{Pallidal movement-related desynchronization is more pronounced in PD}

Because beta band desynchronization in the motor system is a critical feature of normal movement (Crone et al., 1998; 
Table 1. Clinical characteristics of PD patients

\begin{tabular}{|c|c|c|c|c|c|c|c|c|c|c|c|c|}
\hline \multirow[t]{2}{*}{ Pt no. } & \multirow[t]{2}{*}{ Age } & \multirow[t]{2}{*}{ Sex } & \multirow[t]{2}{*}{ Side } & \multirow[t]{2}{*}{ Disease duration, years } & \multirow[t]{2}{*}{ Levodopa equivalent dose, $\mathrm{mg}^{a}$} & \multirow[t]{2}{*}{ Off UPDRS-III } & \multirow[t]{2}{*}{ On UPDRS-III } & \multicolumn{3}{|c|}{ Lead location, $\mathrm{mm}^{b}$} & \multirow[t]{2}{*}{ Movement task } & \multirow[t]{2}{*}{ Motor ECOG } \\
\hline & & & & & & & & Lat & AP & Vert & & \\
\hline 1 & 53 & M & L & 8 & 640 & 55 & 29 & -22.2 & 3.8 & -3.1 & $Y$ & Y \\
\hline 2 & 64 & M & R & 10 & None $^{c}$ & 64 & 31 & 20.5 & 2.5 & -1.9 & $\mathrm{~N}$ & Y \\
\hline 4 & 63 & M & $\mathrm{R}$ & 12 & 845 & 47 & 39 & 21.9 & 1.1 & -3.8 & $\mathrm{~N}$ & Y \\
\hline 5 & 74 & M & L & 14 & 1778 & 50 & 31 & -26.2 & 8.3 & -0.1 & $\mathrm{~N}$ & $\mathrm{~N}$ \\
\hline 6 & 71 & M & $\mathrm{R}$ & 7 & 1240 & 41 & 22 & 22.1 & 5.2 & 0.0 & Y & Y \\
\hline 9 & 65 & M & $\mathrm{R}$ & 7 & 750 & 42 & 23 & 22.4 & 3.4 & -0.5 & $\mathrm{~N}$ & $\mathrm{~N}$ \\
\hline 10 & 46 & M & $\mathrm{R}$ & 5 & 940 & 39 & 21 & 20.4 & 3.9 & -3.3 & $\mathrm{~N}$ & $\mathrm{~N}$ \\
\hline 11 & 59 & M & L & 5 & 790 & 53 & 16 & -20.3 & 2.9 & -0.8 & $\mathrm{~N}$ & $\mathrm{~N}$ \\
\hline 12 & 72 & M & $\mathrm{R}$ & 10 & 1755 & 34 & 27 & 22.3 & 2.8 & -2.0 & Y & Y \\
\hline 13 & 65 & $\mathrm{~F}$ & $\mathrm{R}$ & 11 & 720 & 73 & 32 & 21.6 & 2.5 & -3.6 & $\mathrm{~N}$ & $Y$ \\
\hline 14 & 61 & M & L & 7 & 325 & 39 & 20 & -23.1 & 5.9 & -4.6 & $\mathrm{~N}$ & $\mathrm{~N}$ \\
\hline 19 & 58 & M & L & 13 & 1640 & 42 & 15 & -19.0 & 4.0 & -1.1 & Y & Y \\
\hline 20 & 58 & $\mathrm{~F}$ & L & 10 & 1300 & 37 & 22 & -19.0 & 3.8 & -6.6 & $\mathrm{~N}$ & Y \\
\hline
\end{tabular}

${ }^{a}$ The preoperative levodopa equivalent dose (LEED) was calculated using the following conversion factors: ropinirole $\times 20$; pramipexole $\times 100$; levodopa with decarboxylase inhibitor $\times 1$; controlled release levodopa with decarboxylase inhibitor $\times 0.7$; levodopa with decarboxylase and catechol-0-methyltransferase inhibitor $\times 1.3$ (Wenzelburger et al., 2002). All doses are daily totals.

${ }^{b}$ Location of the midpoint of the recording contact pair in anterior commissure and post-commissure plane.

'This patient was intolerant of levodopa and only took rasagiline.

Lat, Lateral distance from mid-commissural point; AP, anterior-posterior distance from mid-commissural point; Vert, vertical distance from mid-commissural point.

Table 2. Clinical characteristics of dystonia patients

\begin{tabular}{|c|c|c|c|c|c|c|c|c|c|c|c|c|}
\hline \multirow[t]{2}{*}{ Ptno. } & \multirow[t]{2}{*}{ Age } & \multirow[t]{2}{*}{ Sex } & \multirow[t]{2}{*}{ Side } & \multirow[t]{2}{*}{ Dystonia type } & \multirow{2}{*}{$\begin{array}{l}\text { Disease duration, } \\
\text { years }\end{array}$} & \multirow[t]{2}{*}{ Medication, mg } & \multirow[t]{2}{*}{ TWSTRS/BFMDRS } & \multicolumn{3}{|c|}{ Lead location, $\mathrm{mm}^{a}$} & \multirow[t]{2}{*}{ Movement task } & \multirow[t]{2}{*}{ Motor ECoG } \\
\hline & & & & & & & & Lat & AP & Vert & & \\
\hline 1 & 61 & M & R & Cervical & 6 & Baclofen 60, diazepam 20, trihexyphenidyl 6 & $33.75 / 6$ & 19.5 & 3.5 & -1.1 & $\mathrm{~N}$ & $\mathrm{~N}$ \\
\hline 2 & 59 & $\mathrm{~F}$ & $\mathrm{R}$ & Craniocervical & 10 & Cyclobenzaprine 10 & $\mathrm{na} / 11$ & 21.2 & 4.0 & -0.7 & N & Y \\
\hline 3 & 46 & M & $\mathrm{R}$ & Craniocervical & 23 & Clonazepam 1 & $18 / 20$ & 21.4 & 4.7 & -1.6 & N & Y \\
\hline 4 & 46 & $\mathrm{~F}$ & $\mathrm{R}$ & Craniocervical & 14 & Clonazepam 2 & $28 / 9$ & 18.7 & 4.5 & -1.1 & Y & Y \\
\hline 5 & 56 & $\mathrm{~F}$ & $\mathrm{R}$ & Craniocervical & 2 & Cetirizine 10 & $20 / 7$ & 18.6 & 3.5 & -0.4 & Y & Y \\
\hline 6 & 47 & M & $\mathrm{R}$ & Cervical & 5 & Lorazepam 6 & $23 / 12$ & 22.2 & 4.5 & -2.6 & Y & Y \\
\hline 7 & 34 & M & $\mathrm{R}$ & Cervical & 4 & Clonazepam 1, baclofen 20 & $25 / 8$ & 18.2 & 4.4 & -2.0 & Y & Y \\
\hline 8 & 47 & $\mathrm{~F}$ & $\mathrm{~L}$ & DYT1+ & 37 & Trihexyphenidyl 4 & $0 / 24$ & -19.3 & 7.5 & -1.6 & Y & Y \\
\hline 9 & 53 & $\mathrm{~F}$ & $\mathrm{~L}$ & Generalized & 11 & Clonazepam $1^{b}$ & $12 / 51.5$ & -19.6 & 5.3 & -1.2 & Y & Y \\
\hline 10 & 37 & M & R & DYT1+ & 29 & Clonazepam 1 & $0 / 23$ & 21.6 & 6.8 & -0.2 & Y & Y \\
\hline 11 & 57 & $\mathrm{~F}$ & R & Generalized & 40 & Clonazepam 1.5, diazepam 40 & $25 / 26$ & 19.7 & 2.4 & -1.9 & Y & Y \\
\hline 12 & 26 & M & L & Generalized & 7 & LEED $450^{2}$, trihexyphenidyl 6 & $13 / 29$ & -20.3 & 6.3 & -2.7 & Y & Y \\
\hline 13 & 22 & M & $\mathrm{L}$ & DYT1+ & 14 & Baclofen 50, trihexyphenidyl 15 & $\mathrm{na} / 30.5$ & -23.1 & 1.5 & -4.2 & Y & $\mathrm{N}$ \\
\hline 14 & 35 & M & $\mathrm{R}$ & Generalized & 1 & Baclofen 30, LED 600; cyclobenzaprine 15 & $18 / 11$ & 21.2 & 4.7 & -2.1 & $\mathrm{~N}$ & $Y$ \\
\hline
\end{tabular}

a Location of the recording contact in anterior commissure and post-commissure plane.

${ }^{b}$ Medication for Patient 9 was held $2 \mathrm{~d}$ prior to surgery.

DYT medication, Medications for dystonia; TWSTERS, Toronto Western Spasmodic Torticollis Rating Scale (motor severity score); BFMDRS, Burke-Fahn-Marsden Dystonia Rating Scale (movement subscale); Lat, lateral distance from mid-commissural point; AP, anterior-posterior distance from mid-commissural point; Vert, vertical distance from mid-commissural point; na, not available.

Taniguchi et al., 2000), and beta band activity in PD in the pallidum is elevated at rest, we hypothesized that movement initiation might require a more pronounced decrease in pallidal beta band activity, compared with non-parkinsonian conditions. We therefore investigated how pallidal and M1 oscillatory activity changes with movement. Seven PD patients and 10 dystonia patients participated in either an elbow movement task or an iPad armreaching task, which showed similar levels of movement-related power changes. We separated each recording into hold and movement epochs based on surface electromyography recordings (Fig. 3A). Spectral power for each hold and movement epochs $>1$ s were calculated and averaged for the pallidum (Fig. $3 B$ ) and M1. These values were also compared with those recorded during rest, when the patient is not engaged in a task (Fig. 3B). Movement-related power changes were measured by subtracting the averaged power spectra during movement from the averaged power spectra during hold phase and calculating the percentage power change from the hold phase power. PD patients had greater alpha and beta band desynchronization with movement compared with those of dystonia patients, and this difference was evident in individual recordings ( $P D$ vs dystonia: theta: $\mathrm{p}=0.1613$, alpha: $\mathrm{p}=0.0226$, low beta: $p=0.0413$, high beta: $p=0.0062$; post hoc FDR-adjusted Wilcoxon rank sum test; Fig. $3 C$ ). Thus, voluntary movement suppresses elevated pallidal beta band synchronization. Movement is often associated with increases in gamma band activity in the basal ganglia (Cassidy et al., 2002), but the movement-related increase in pallidal low gamma $(30-70 \mathrm{~Hz})$ activity in $\mathrm{PD}$ was less pronounced than in dystonia ( $p=0.0170$ post hoc FDR-adjusted Wilcoxon rank sum test). In M1, differences in movement- 

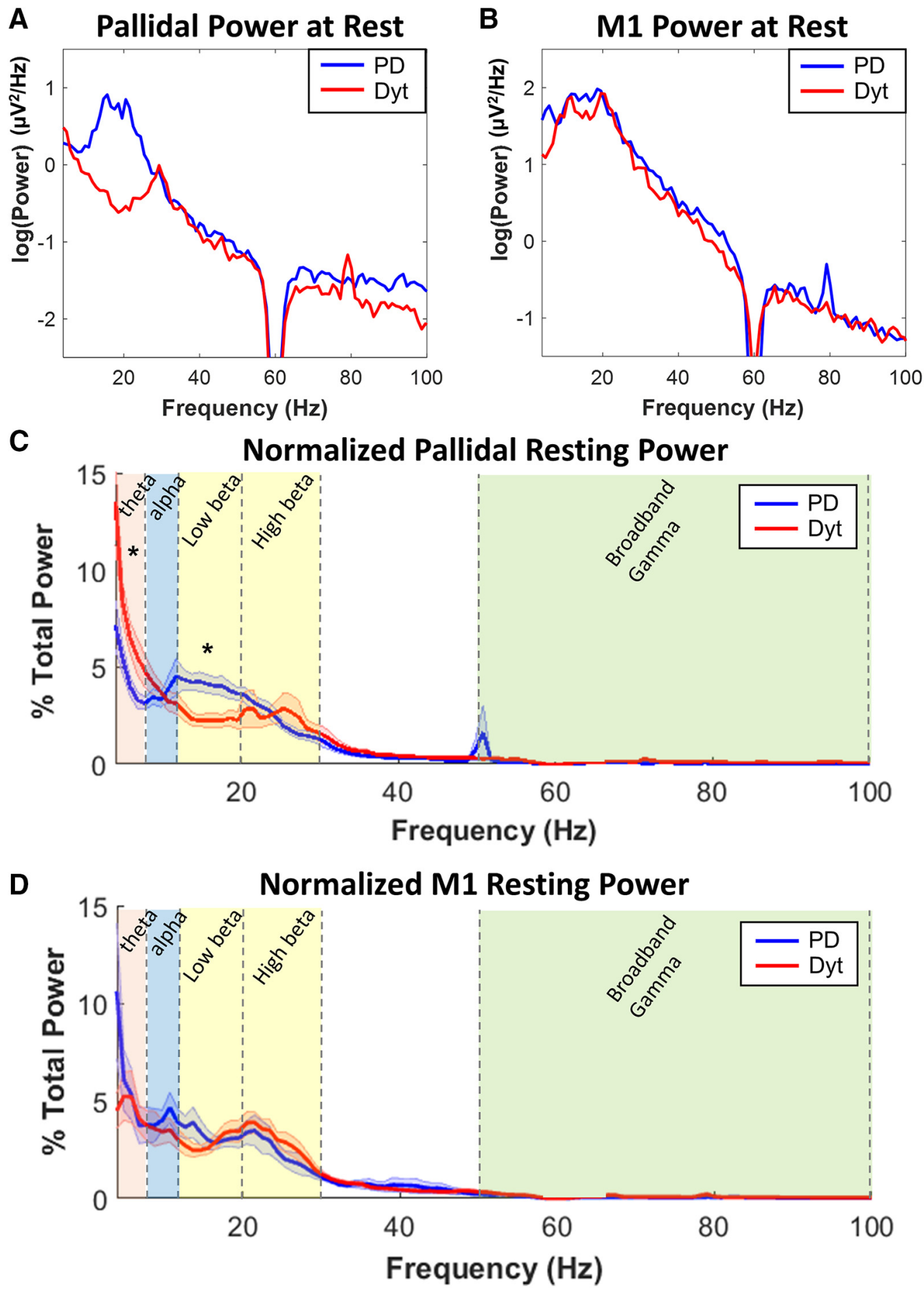

Figure 2. Pallidal and M1 spectral power in the resting state for PD and dystonia. $A$, Log-transformed resting pallidal PSD graphs from a PD patient (blue) and a dystonia patient (red) showing differences in beta frequency power peak. $\boldsymbol{B}$, Log-transformed resting M1 PSD graphs from a PD patient (blue) and a dystonia patient (red) showing similar power spectra. All signals were notch-filtered at $60 \mathrm{~Hz}$. C, Averages of normalized resting pallidal spectral power for $20 \mathrm{PD}$ (blue line) and 14 dystonia (red line) with their respective SEM (shaded). Asterisks indicate frequency bands showing significant difference between the two groups in theta and low beta bands. ${ }^{*} p<0.05$; post hoc FDR-adjusted Wilcoxon rank sum test. $D$, Averages of normalized resting M1 spectral power for 11 PD (blue line) and 12 dystonia (red line) with their respective SEM (shaded) demonstrating no differences in spectral power.

related changes between PD and dystonia did not reach significance (data not shown).

Disease-specific differences in pallidal beta oscillations are driven by the amplitude of beta bursts

Beta band oscillations in the motor system are often studied by computing averaged power spectra over many oscillatory cycles, but examination of time series data shows that beta oscillations tend to be packaged in bursts whose amplitude and duration may encode information germane to movement kinematics and to therapeutic mechanisms in movement disorders (Tinkhauser et al., 2017a,b). Bursts in beta band oscillatory activity were characterized using these recently published methods (Tinkhauser et al., 2017a,b; Fig. 4A,B). We found higher mean pallidal beta burst 


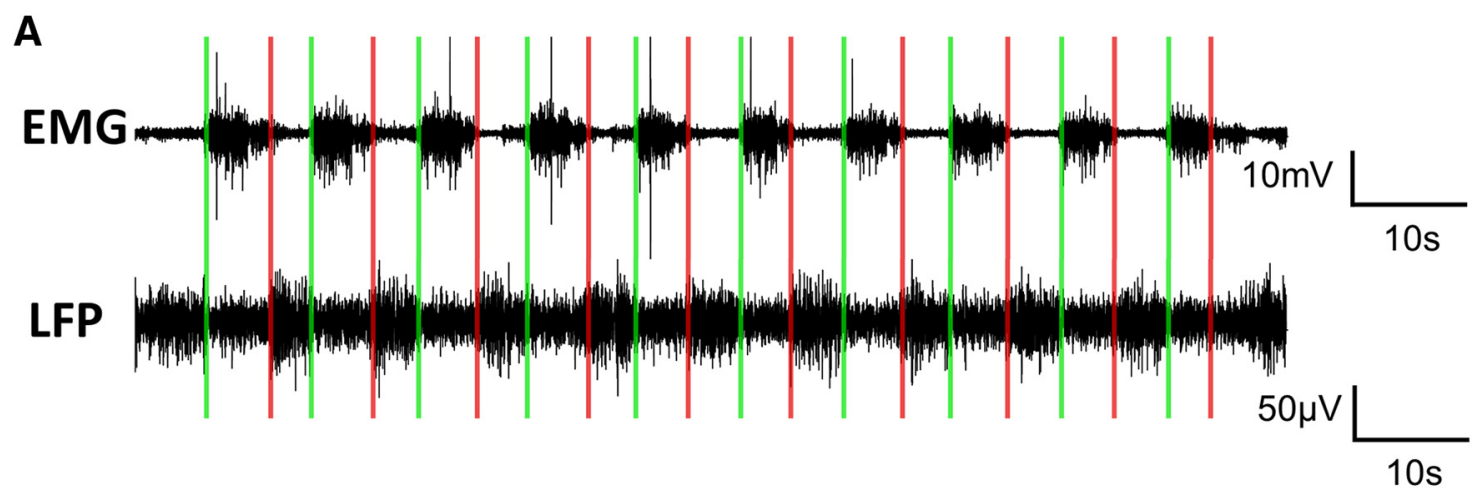

B
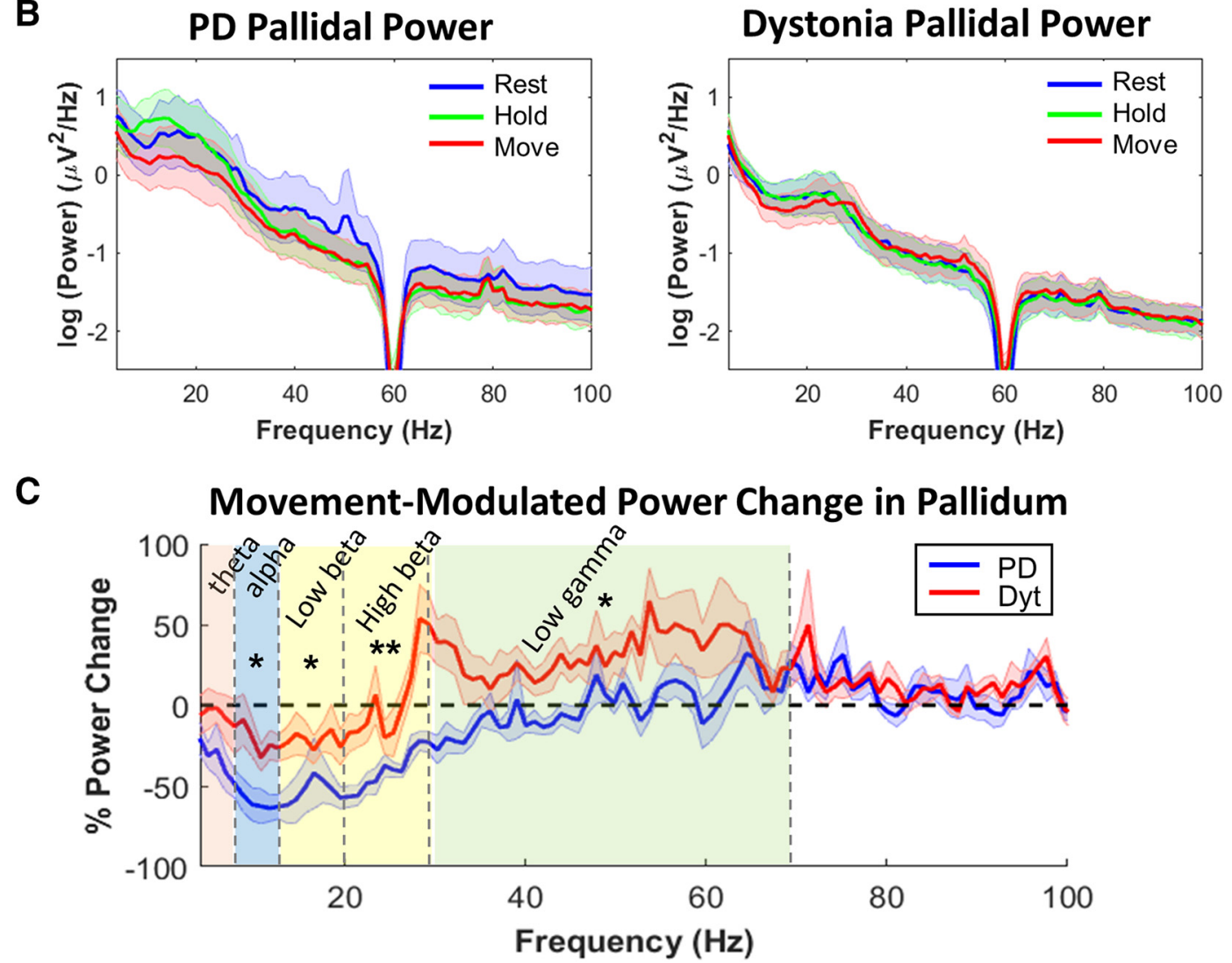

Figure 3. Movement-modulated power changes in pallidal LFP and M1 ECoG potential of PD and dystonia patients. A, An example of surface electromyography (EMG, top) recorded from the biceps muscle and pallidal LFP (bottom) during a voluntary elbow movement task. Start of each movement epoch is marked by green lines and end of movement is marked by red lines. Time stamps of movement start and end were used to parse the recording into hold epochs and movement epochs. $\boldsymbol{B}$, Comparison of mean pallidal LFP log spectral powers \pm SEM for all seven PD patients (left) and all 10 dystonia patients (right) during rest (blue line) and hold epochs (green line) or movement epochs (red line) during an arm movement task. $C$, Grouped analysis for averages \pm SEM of movement-modulated power changes in the pallidal LFP for seven PD patients (blue line) and 10 dystonia patients (red line) who underwent an arm movement task. Movement-related power changes were calculated by subtracting mean hold power from mean movement power and normalizing the power change to hold power. ${ }^{*} p<0.05,{ }^{* *} p<0.01 ; p 0 s t$ hoc FDR-adjusted Wilcoxon rank sum test.

amplitude in PD than dystonia $(p=0.0060$; post hoc FDRadjusted Wilcoxon rank sum test; Fig. $4 C$, right), but no difference in the mean beta burst duration (PD vs dystonia: $p=0.0772$; Wilcoxon rank sum test; Fig. $4 C$, middle) or in the distribution of beta burst durations (PD vs dystonia for all bin durations: $F_{(1,8)}=$ 0.1140, $p=0.9987$; two-way ANOVA; Fig. $4 C$, left). There was also no difference in burst frequency between disease states (PD vs dystonia: $p=0.0741$; Wilcoxon rank sum test; data not shown). Thus, the observed disease-specific differences in beta pallidal spectral power averaged over time (Fig. 2A,C), were driven by differences in the amplitude but not the duration or frequency of individual bursts. These differences in beta bursts were specific to the pallidum, as M1 recordings showed similar distribution of beta burst duration (PD vs dystonia for all bin durations: $F_{(1,8)}=0.3513, p=0.9443$; two-way ANOVA; Fig. $4 D$, left), mean burst duration (PD vs dystonia: $p=0.9264$; Wilcoxon rank sum test; Fig. $4 D$, middle), mean burst amplitudes between the two disease groups (PD vs dystonia: $p=0.1985$; Wilcoxon rank sum test; Fig. $4 D$, right), as well as burst frequency (PD vs dystonia: $p=0.9754$; data not shown).

Greater pallido-cortical beta coherence in PD compared with dystonia

In humans, the internal pallidum is the major output structure of the basal ganglia, and strongly modulates cortical function (via synaptic connections in the motor thalamus; DeLong, 1990). We 
A
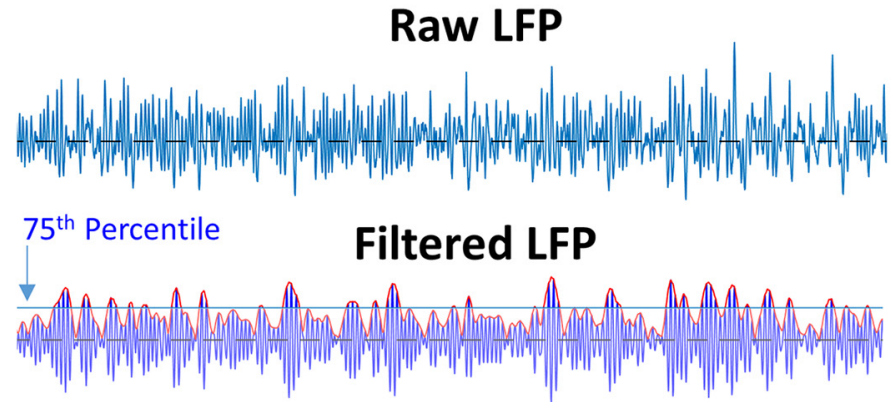

B

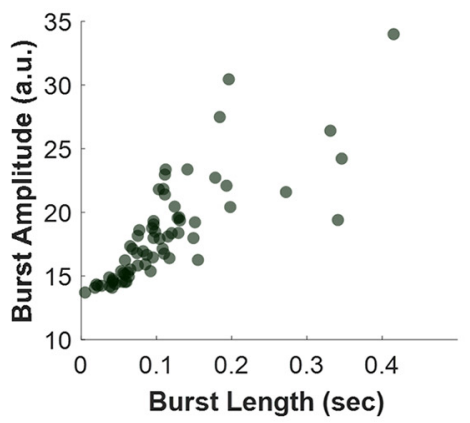

C
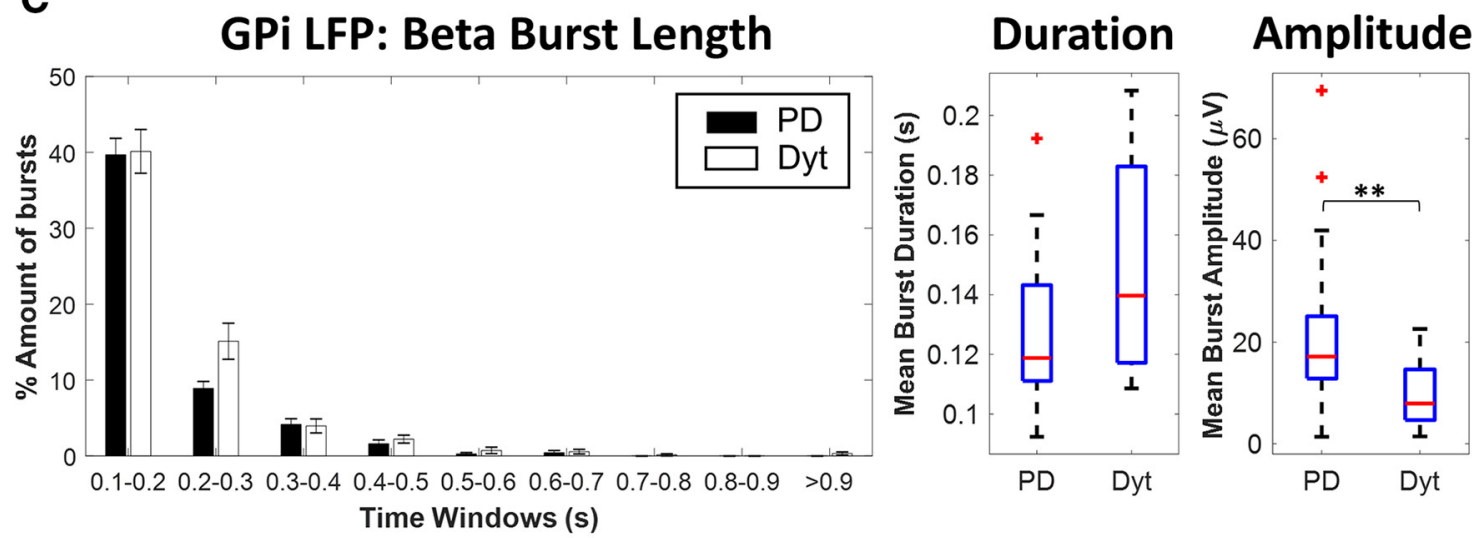

D
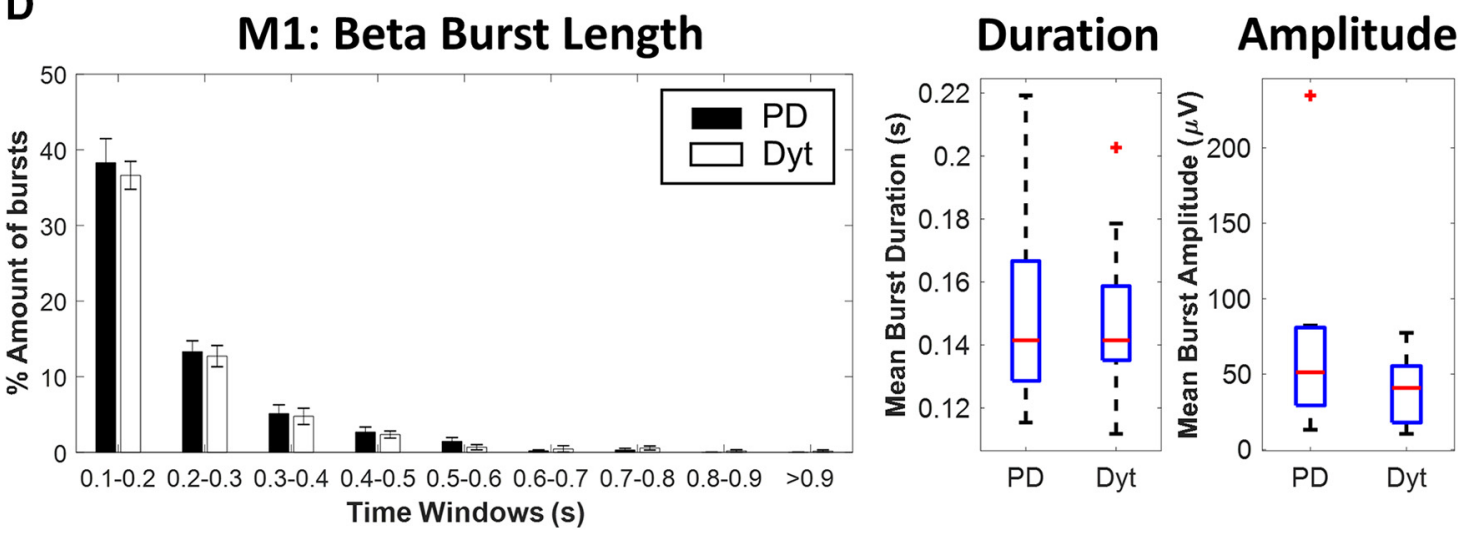

Figure 4. Beta-burst activity in pallidal LFP and M1 ECOG potential in PD and dystonia. $A$, Each LFP or ECoG potential signal was bandpass filtered ( $\pm 4 \mathrm{~Hz}$ ) around individual beta peak frequency, and the amplitude envelope of the beta activity envelope was obtained. A threshold was set at the 75th percentile of the beta amplitude. The onset of a burst was defined as when the filtered signal crossed the threshold amplitude and the end of the burst defined as when the amplitude fell below threshold. $\boldsymbol{B}$, An example of a scatter plot showing the distribution of burst amplitudes and lengths from A. C, Left, Distribution of pallidal LFP beta-burst durations in PD (black bars) and dystonia (white bars; $F_{(1,8)}=0.1140, p=0.9987$; two-way ANOVA). Middle, Boxplot showing distribution of mean pallidal LFP beta-burst duration for $20 \mathrm{PD}$ and 14 dystonia patients ( $p=0.0772$; Wilcoxon rank sum test; red line indicates median and box shows 25 th -75 th percentile values). Right, Boxplot showing distribution of mean pallial LFP beta-burst amplitude for $20 \mathrm{PD}$ and 14 dystonia patients $\left(p=0.0060\right.$; ${ }^{* *} p<0.01$; Wilcoxon rank sum test; red line indicates median and box shows 25th-75th percentile values). $D$, Left, Distribution of M1 ECOG potential beta burst durations in PD (black bars) and dystonia (white bars; $F_{(1,8)}=0.3513, p=0.9443$; two-way ANOVA). Middle, Boxplot showing mean M1 beta-burst duration for $10 \mathrm{PD}$ and 12 dystonia patients ( $p=0.9264$; Wilcoxon rank sum test; red line indicates median and box shows 25 th-75th percentile values). Right, Boxplot showing distribution of mean M1 beta burst amplitude for 10 PD and 12 dystonia patients ( $p=0.1985$; Wilcoxon rank sum test; red line indicates median and box shows 25 th-75th percentile values).

therefore evaluated disease-specific differences in pallido-cortical functional connectivity using simultaneous field potential recordings from subdural ECoG strips and pallidal DBS lead in 11 PD and 12 dystonia patients. PD patients had elevated low beta band coherence between GP and primary motor cortex compared with dystonia patients (PD vs dystonia: theta: $p=0.6724$, alpha: $p=0.6724$, low beta: $p=0.0248$, high beta: $p=0.6724$, broadband gamma: $p=1.0$, HFO: $\mathrm{p}=p=0.6724$; post hoc FDR- adjusted Wilcoxon rank sum; Fig. 5A). This difference was specific to the primary motor area, as coherence between the pallidum and primary somatosensory cortex did not differ between disease groups (data not shown).

To determine whether disease-specific patterns of pallidocortical coherence were driven primarily by phase effects or amplitude effects, we analyzed phase coherence and amplitude coherence for each patient population separately. PD and dysto- 
nia patients did not differ in theta or lowbeta GP-M1 amplitude coherence (PD vs dystonia: theta: $p=0.1858$, low-beta: $p=$ 0.1858 ; post hoc FDR-adjusted Wilcoxon rank sum; Fig. 5B). However, dystonia patients had higher theta frequency phase coherence than PD, whereas PD had higher low-beta phase coherence than dystonia (PD vs dystonia: theta: $p=$ 0.0148 , low-beta: $p=0.0289$; post hoc FDR-adjusted Wilcoxon rank sum; Fig. 5D).

\section{GP DBS stimulation reduces pallidal beta power and} pallido-cortical beta coherence in PD To investigate whether therapeutic DBS in PD corrects exaggerated beta oscillatory activity in GP and in GP-motor cortex coherence, we recorded from M1 and pallidal LFP signals from contacts immediately above and below the active GP contact in four PD patients. An example of a continuous pallidal LFP recording in the DBS OFF/ON/OFF condition is shown in Figure 6A. The corresponding pallidal LFP time-frequency spectrogram demonstrated suppression of beta power during periods of GPi DBS stimulation as well during UPDRS clinical testing (Fig. $6 B)$. To quantify the effects of DBS on pallidal resting power, log spectral power calculated during DBS OFF, 2 mA DBS ON, $4 \mathrm{~mA}$ DBS ON, and DBS OFF washout showed decreased beta frequency power during DBS stimulation, which returned to baseline after a $30 \mathrm{~s}$ washout period (Fig. 6C). Clinical assessment of contralateral arm UPDRS III subscores demonstrated improvement of tremor and bradykinesia during DBS, which returned to baseline after stimulation was off (Fig. 6C, insets). Group comparison of four PD patients during DBS OFF/ON/OFF recordings showed decreased total beta power in the DBS ON and compared with pre-DBS and post-DBS states $\left(F_{(2)}=13.42, p=0.0061\right.$, repeated-measure ANOVA; PreDBS vs DBS ON: $p=0.0109$; DBS ON vs Post-DBS: $p=0.0090$; repeated post hoc Tukey's test; Fig. 6D). The effect of DBS on beta power was specific to the pallidum as DBS had no effect on M1 beta power $\left(F_{(2)}=1.3773, p=0.3219\right.$, repeated-measure ANOVA; Pre-DBS vs DBS ON: $p=0.3239$; DBS ON vs PostDBS: $p=0.4791$; post hoc Tukey's test; Fig. $6 E$ ).

We further explored changes in pallido-M1 interactions during pallidal DBS stimulation in PD patients (Fig. $6 F$ ). DBS stimulation reduced both pallido-cortical beta phase synchrony $\left(F_{(2)}=\right.$ 5.98, $p=0.0312$, repeated measure ANOVA; Pre-DBS vs DBS ON: $p=0.0055$; DBS ON vs Post-DBS: $p=0.2758$; post hoc Tukey's test; Fig. $6 G)$ and pallido-cortical beta amplitude coupling $\left(F_{(2)}=8.7126, p=0.0168\right.$, repeated-measure ANOVA; Pre-DBS vs DBS ON: $p=0.0151$; DBS ON vs Post-DBS: $p=$ 0.0740; post hoc Tukey's test; Fig. $6 H$ ).

Because DBS at the STN has been shown to reduce cortical PAC (de Hemptinne et al., 2015), we tested whether acute pallidal DBS reduced PAC in the primary motor cortex. We found a trend toward reduction of beta phase to broadband gamma amplitude coupling in PD that did not reach significance (data not shown). Resting-state motor cortex PAC in PD was more than in isolated dystonia, consistent with prior reports (de Hemptinne et al., 2013).

\section{Discussion}

We recorded pallidal LFPs and motor cortex ECoG potentials in patients undergoing DBS surgery for akinetic-rigid PD or isolated dystonia, to evaluate disease-specific differences in pallidal and pallido-cortical oscillatory phenomena, and to investigate mechanisms of pallidal DBS. We found that in the resting state, beta power at $13-20 \mathrm{~Hz}$ is relatively elevated in $\mathrm{PD}$, whereas theta power is relatively elevated in dystonia. This elevation in beta band oscillations in PD is driven largely by the amplitude and not the duration or frequency of individual "bursts" of beta activity, and it is reduced by voluntary movement, consistent with prior studies (Gillies et al., 2017; Tsiokos et al., 2017). Resting-state low beta pallido-cortical coherence is elevated in PD and is reduced by therapeutic pallidal DBS. Our findings support the theory that elevated beta oscillatory synchronization in the basal gangliathalamocortical-motor network is a hallmark of the parkinsonian state, point to the importance of the globus pallidus as a critical site for this elevated synchrony, and suggest a mechanism for stimulation-mediated suppression of the influence of basal ganglia output on cortical function. 
A
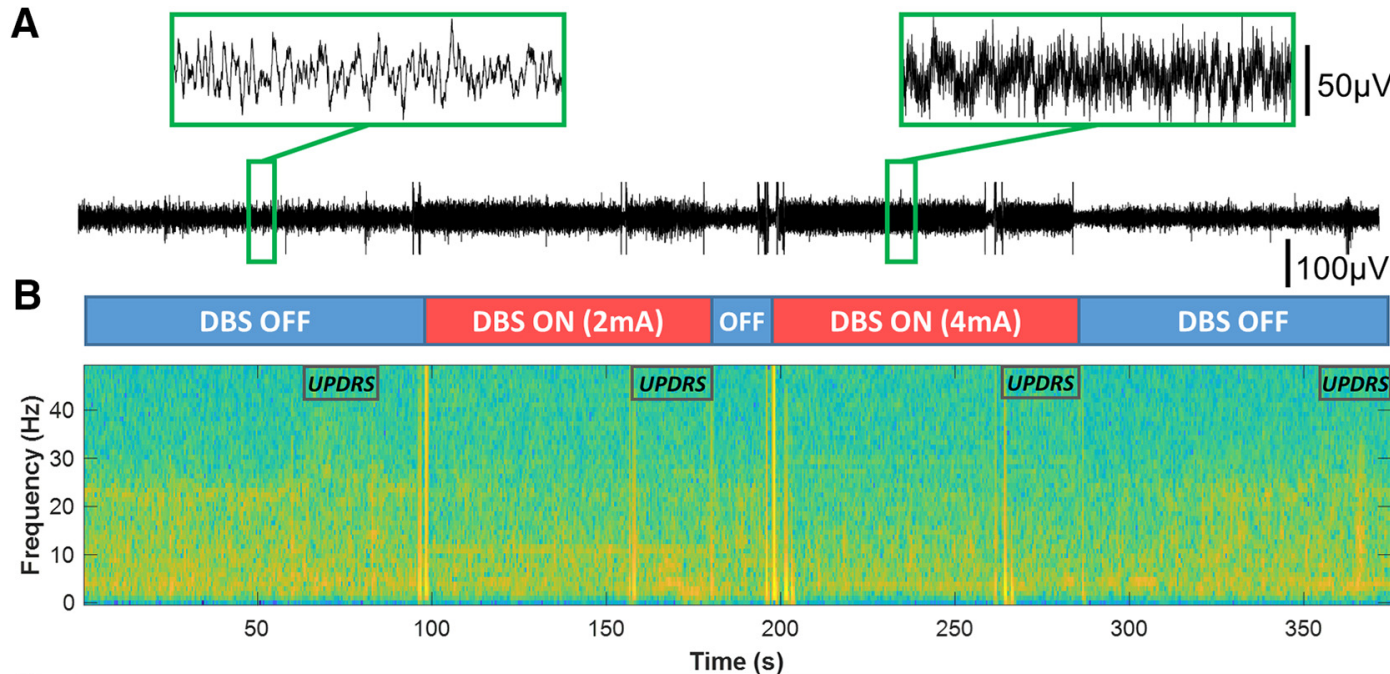

C
DBS OFF
DBS ON (2mA)
OFF
DBS ON (4mA)
DBS OFF
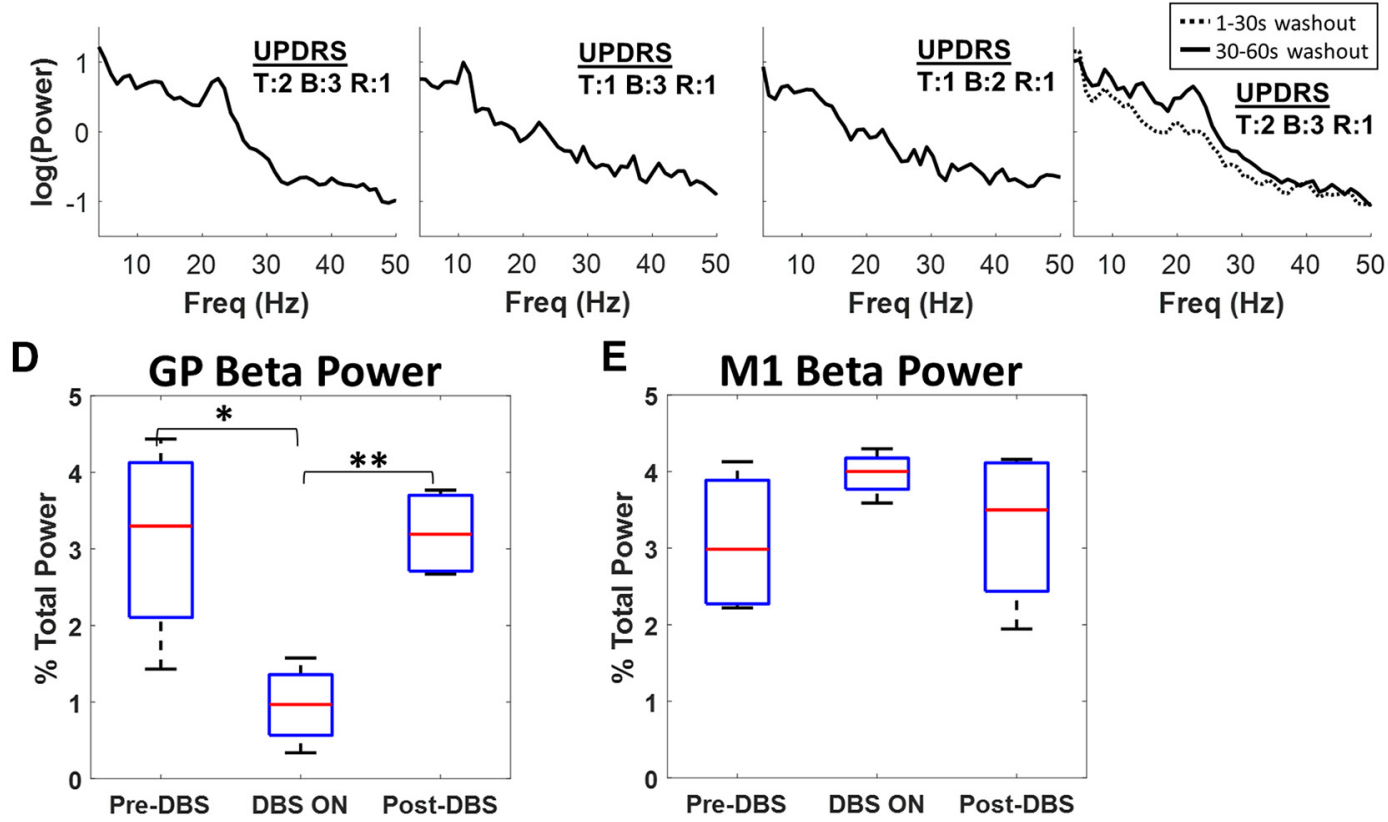

F

M1-GP LFP Coherence
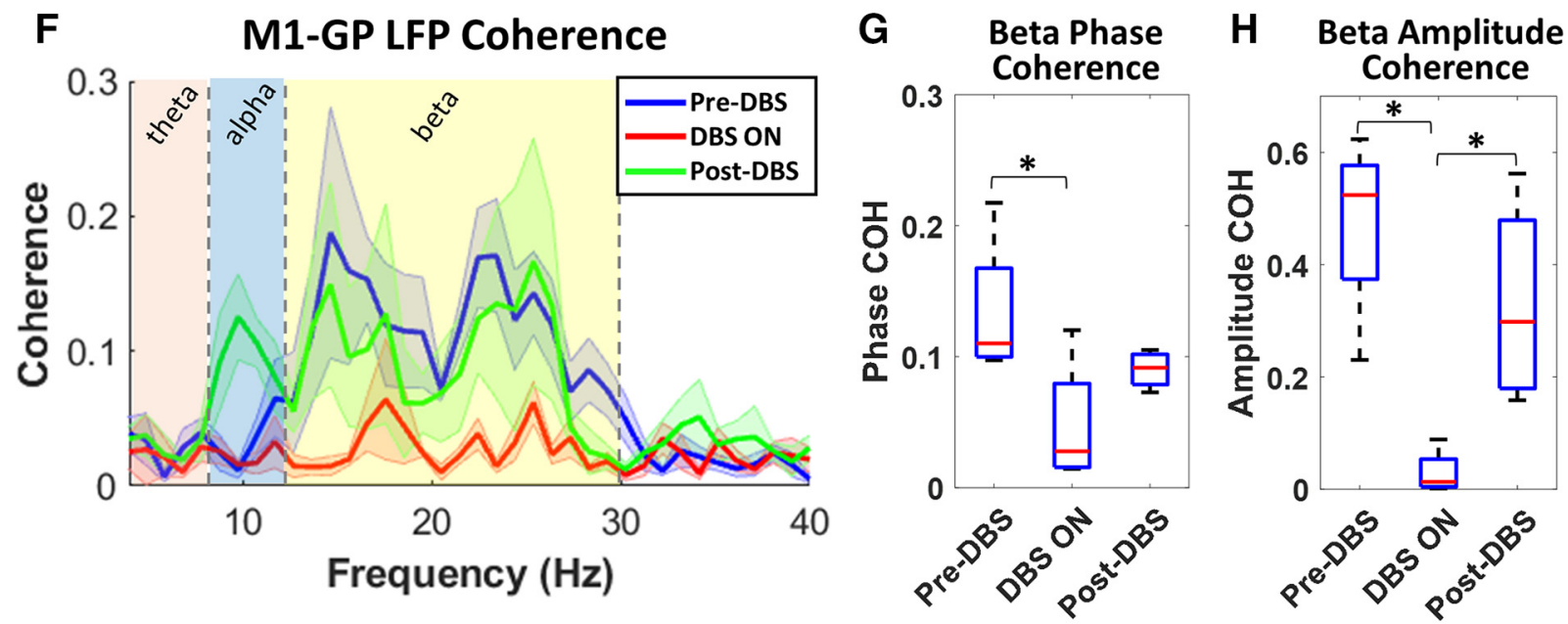

Figure 6. Effect of therapeutic high-frequency GPi DBS on pallidal beta power and pallido-M1 beta coherence. A, Pallidal LFP recorded from Contacts 0 to 2 pre-, during-, and post-DBS stimulation (monopolar using Contact 1: $130 \mathrm{~Hz}, 90 \mu \mathrm{S}, 2-4 \mathrm{~mA}$ ). Stimulation conditions correspond to schematic timeline shown in $\boldsymbol{B}$. Insets represent magnified areas indicated by the green box. Scale bars are on the right of traces. $\boldsymbol{B}$, Time-frequency spectrogram showing power changes in the DBS OFF/ON conditions indicated by the schematic timeline. UPDRS boxes indicated periods when clinical testing was performed to assess patient symptoms. Warmer colors indicate higher power. Time axis is the same as in $\boldsymbol{A}$. $\boldsymbol{C}, \log$ PSDs of 30 s pallidal (Figure legend continues.) 


\section{Oscillatory signature of rigid-akinetic PD}

Analysis of invasive recordings in humans have led to the hypothesis that bradykinesia arises from excessively synchronized oscillatory activity in the basal ganglia thalamocortical motor loop (Brown, 2003; Oswal et al., 2013). The initial evidence for this was derived from STN LFP recordings in PD patients on and off dopamine, or on and off DBS, showing that effective therapy reduces the amplitude of the dominant motor beta rhythm (Priori et al., 2004; Kühn et al., 2008; Bronte-Stewart et al., 2009). Subsequently, other metrics of beta synchronization, such as the entrainment of high-frequency activity to the phase of the beta rhythm in STN (López-Azcárate et al., 2010) and cortex (de Hemptinne et al., 2013), have been found to be prominent in PD patients off medication, and reduced by medications (Swann et al., 2015) and STN DBS (de Hemptinne et al., 2015).

Although many forms of neuronal synchronization in the motor network are modulated by therapy, it has been difficult to identify a simple measurement based on field potential recording at a single brain site, such as spectral power at beta frequency in the resting state, that is clearly elevated in PD compared with non-parkinsonian conditions. In motor cortex, ECoG studies of movement disorders patients compared with those without movement disorders have not shown resting differences in spectral power (Crowell et al., 2012; Kondylis et al., 2016). Likewise, a comparison of resting STN LFP recording in PD and isolated dystonia showed no apparent differences (Wang et al., 2016), although a smaller study did suggest increased beta band LFP power in PD (Geng et al., 2017). Here, in a large series of human recordings, we add to the evidence from three prior smaller series (Silberstein et al., 2003; Weinberger et al., 2012; Jimenez-Shahed et al., 2016) pointing to the GP as site in the motor circuit with resting-state elevation in LFP beta band oscillations compared with non-parkinsonian movement disorders. Thus, conceptual or computation models of bradykinesia in PD should incorporate elevated pallidal beta band activity as a critical component. Globus pallidus may provide a more robust site for detection of a disease-specific biomarker of the parkinsonian state, compared with other structures in the motor network. Because LFP beta band spectral power is readily detected by currently available totally implantable neural interfaces (Quinn et al., 2015; Swann et al., 2018), this finding suggests a strategy for "adaptive" (feedback controlled) DBS in PD using pallidal beta oscillations, a strategy currently under exploration for STN-DBS (Meidahl et al., 2017).

$\leftarrow$

(Figure legend continued.) LFPs recorded during the following conditions: leftmost: DBS OFF; second from left: DBS ON (2 mA); second from right: DBS ON (4 mA); and rightmost: DBS washout during the first $30 \mathrm{~s}$ (dotted line) and last $30 \mathrm{~s}$ (solid line). UPDRS scores during each condition is shown. T, tremor; $B$, bradykinesia; $R$, rigidity. $D$, Group comparison of four PD patients during DBS OFF/ON/OFF recordings showed decreased total beta power in the DBS ON and compared with pre-DBS and post-DBS states $(F=13.42, p=0.0061$, repeated-measure ANOVA; Pre-DBS vs DBS ON: $p=0.0109$; DBS ON vs Post-DBS: $p=0.0090$; posthoc Tukey's test; $\left.{ }^{*} p<0.05\right)$. $E$, GPi DBS had no effect on M1 beta power $(F=1.3773, p=0.3219$, repeatedmeasure ANOVA; Pre-DBS vs DBS ON: $p=0.3239 ;$ DBS ON vs Post-DBS: $p=0.4791 ;$ post hoc Tukey's test). $\boldsymbol{F}$, Averages of M1-pallidal coherence for four PD patients pre- (blue line), during(red line), and post- (green) GPi DBS demonstrating reduction of beta coherence during GPi DBS. G, Boxplots of average beta phase coherence pre-, during-, and post-DBS showing reduction of beta-phase synchrony during GPistimulation $(F=5.98, p=0.0312$, repeated-measure ANOVA; Pre-DBS vs DBS ON: $p=0.0055$; DBS ON vs Post-DBS: $p=0.2758$; post hoc Tukey's test; ${ }^{*} p<0.05$; red line indicates median and box shows 25 th -75 th percentile values). $\boldsymbol{H}$, Boxplots of average beta amplitude coherence pre-, during-, and post-DBS showing difference between DBS ON and DBS washout period $(F=8.7126, p=0.0168$, repeated-measure ANOVA; Pre-DBS vs DBS ON: $p=0.0151$; DBS ON vs Post-DBS: $p=0.0740$; post hoc Tukey's test, ${ }^{*} p<0.05$; red line indicates median and box shows 25 th-75th percentile values).

\section{Pallidal oscillations entrain primary motor cortex at} frequencies specific to abnormal motor signs

The internal pallidum, as the primary site of basal ganglia outflow in primates, is positioned to exert a strong modulatory effect on motor cortex, via the thalamus. Although the original "rate model" postulated this influence to be expressed by rates of neuronal firing (DeLong, 1990), here we propose that it is based on coherence. Through combined pallidal and ECoG studies, we showed that specific patterns of oscillatory activity in the pallidum are reflected in coherence between GP and primary motor cortex, and that this elevated coherence is primarily based on phase relationship between these structures. The critical role of phase coherence between functionally related structures of the nervous system is underscored by the "communication through coherence" hypothesis, which posits that structures that oscillate together become functionally connected by increasing the probability that action potentials from one structure arrive at the related one (in this case, via a thalamic synapse) at a phase of transmembrane voltage fluctuations that is most likely to trigger suprathreshold depolarization (Fries, 2005).

The present work adds to the growing evidence that specific manifestations of movement disorders are related to elevated phase coherence between basal ganglia and motor cortex, at characteristic frequencies. Consistent with our work, a study that combined pallidal LFP recording with scalp EEG in PD (Williams et al., 2002) showed high beta coherence between pallidum and cortex in akinetic-rigid PD which was reduced as symptoms were ameliorated by levodopa. A combined LFP and EEG study of isolated dystonia likewise showed prominent pallido-cortical theta coherence which was reduced by therapeutic DBS (Barow et al., 2014).

\section{A unifying hypothesis for the efficacy of DBS in movement disorders}

One mystery of the efficacy of DBS in movement disorders is that both STN and pallidal DBS have remarkably similar motor benefits for PD in most randomized comparisons (Burchiel et al., 1999; Anderson et al., 2005; Okun et al., 2009; Follett et al., 2010; Weaver et al., 2012). Further, DBS at both targets have similar benefits in isolated dystonia, a movement disorder that does not usually involve dopamine loss (Ostrem et al., 2011, 2017). This suggests a common mechanism for DBS at both targets in both disorders. One contemporary theory of the mechanism of STN DBS in PD focuses on retrograde entrainment of the "hyperdirect" corticosubthalamic pathway (Gradinaru et al., 2009; Li et al., 2012), but that proposed mechanism is unlikely to apply to pallidal stimulation as a hyperdirect cortical input to the pallidum has not been demonstrated.

Here we show that pallidal DBS strongly reduces pallidal beta oscillations and pallido-cortical beta coherence. It has previously been established that STN DBS in PD results in pallidal beta desynchronization (Brown et al., 2004) and that in isolated dystonia, pallidal DBS suppresses theta-alpha oscillations in the GPi and pallido-cortical theta-alpha coherence in dystonia (Barow et al., 2014). Taking these results together, we suggest a unifying hypothesis for the mechanism of basal ganglia DBS (both STN and GP targets) in movement disorders (both PD and dystonia): suppression of exaggerated coherence between basal ganglia output and cortex. Computational studies support the view that basal ganglia DBS at $>100 \mathrm{~Hz}$ could suppress interstructure coherence across a broad frequency range of oscillatory rhythms (Holt and Netoff, 2014; Cagnan et al., 2015), encompassing rhythms that drive diverse motor signs: theta for dystonia (Liu et 
al., 2002), alpha or "double tremor frequency" for PD tremor (Timmermann et al., 2003), beta for bradykinesia (Oswal et al., 2013), and gamma for dyskinesia/chorea (Swann et al., 2016; Miocinovic et al., 2018). The resulting "functional disconnection" between basal ganglia and cortex might then release cortical neuronal pools from pathological entrainment to the phase of network oscillations (de Hemptinne et al., 2015; Malekmohammadi et al., 2018).

\section{Study limitations}

Data were collected on macroelectrodes after MER recording, which can lead to microlesional effects that results in symptom improvement (Koop et al., 2006). Between-subject comparisons of spectral power typically entail a normalization method, which may affect the results. Here we used normalization by total spectral power, a standard in the literature, but disease-specific differences in pallidal spectral power are also apparent without normalization (Fig. $2 A$ ). The effects of therapeutic DBS in dystonia are typically seen after several weeks or months of stimulation, therefore we did not record the effects of acute DBS stimulation in the intraoperative setting on pallidal oscillations or pallidal-cortical coherence, which was recently reported (Barow et al., 2014). The chronic network effects of pallidal stimulation in PD and dystonia would need to be validated using stimulators with sensing capabilities (Swann et al., 2018). Finally, both in our study and in prior ones (Silberstein et al., 2003; Weinberger et al., 2012; Jimenez-Shahed et al., 2016), quadripolar pallidal DBS leads are placed with ventral contacts in the internal pallidum and dorsal contacts in the external pallidum. Thus, it is likely that neuronal activity in both structures contribute to pallidal recordings.

\section{Conclusions}

Akinetic-rigid PD and isolated dystonia are associated with disease-specific patterns of elevated oscillatory synchronization in the pallidum and in the phase relationship between pallidum and cortex. Therapeutic DBS in PD suppresses pallidal oscillatory activity and pallido-cortical coherence, reducing the influence of diseased basal ganglia on cortical neuronal activity. This mechanism could account for the therapeutic effect of DBS at multiple basal ganglia targets in multiple disease states.

\section{References}

Anderson VC, Burchiel KJ, Hogarth P, Favre J, Hammerstad JP (2005) Pallidal vs subthalamic nucleus deep brain stimulation in parkinson disease. Arch Neurol 62:554-560. CrossRef Medline

Barow E, Neumann WJ, Brücke C, Huebl J, Horn A, Brown P, Krauss JK, Schneider GH, Kühn AA (2014) Deep brain stimulation suppresses pallidal low frequency activity in patients with phasic dystonic movements. Brain 137:3012-3024. CrossRef Medline

Bronte-Stewart H, Barberini C, Koop MM, Hill BC, Henderson JM, Wingeier B (2009) The STN beta-band profile in Parkinson's disease is stationary and shows prolonged attenuation after deep brain stimulation. Exp Neurol 215:20-28. CrossRef Medline

Brown P (2003) Oscillatory nature of human basal ganglia activity: relationship to the pathophysiology of Parkinson's disease. Mov Disord 18:357363. CrossRef Medline

Brown P, Oliviero A, Mazzone P, Insola A, Tonali P, Di Lazzaro V (2001) Dopamine dependency of oscillations between subthalamic nucleus and pallidum in Parkinson's disease. J Neurosci 21:1033-1038. CrossRef Medline

Brown P, Mazzone P, Oliviero A, Altibrandi MG, Pilato F, Tonali PA, Di Lazzaro V (2004) Effects of stimulation of the subthalamic area on oscillatory pallidal activity in Parkinson's disease. Exp Neurol 188:480 - 490. CrossRef Medline

Burchiel KJ, Anderson VC, Favre J, Hammerstad JP (1999) Comparison of pallidal and subthalamic nucleus deep brain stimulation for advanced
Parkinson's disease: results of a randomized, blinded pilot study. Neurosurgery 45:1375-1382; discussion 1382-1384. CrossRef Medline

Cagnan H, Duff EP, Brown P (2015) The relative phases of basal ganglia activities dynamically shape effective connectivity in Parkinson's disease. Brain 138:1667-1678. CrossRef Medline

Cassidy M, Mazzone P, Oliviero A, Insola A, Tonali P, Di Lazzaro V, Brown P (2002) Movement-related changes in synchronization in the human basal ganglia. Brain 125:1235-1246. CrossRef Medline

Crone NE, Miglioretti DL, Gordon B, Sieracki JM, Wilson MT, Uematsu S, Lesser RP (1998) Functional mapping of human sensorimotor cortex with electrocorticographic spectral analysis: I. Alpha and beta eventrelated desynchronization. Brain 121:2271-2299. CrossRef Medline

Crowell AL, Ryapolova-Webb ES, Ostrem JL, Galifianakis NB, Shimamoto S, Lim DA, Starr PA (2012) Oscillations in sensorimotor cortex in movement disorders: an electrocorticography study. Brain 135:615-630. CrossRef Medline

de Hemptinne C, Ryapolova-Webb ES, Air EL, Garcia PA, Miller KJ, Ojemann JG, Ostrem JL, Galifianakis NB, Starr PA (2013) Exaggerated phase-amplitude coupling in the primary motor cortex in Parkinson disease. Proc Natl Acad Sci U S A 110:4780-4785. CrossRef Medline

de Hemptinne C, Swann NC, Ostrem JL, Ryapolova-Webb ES, San Luciano M, Galifianakis NB, Starr PA (2015) Therapeutic deep brain stimulation reduces cortical phase-amplitude coupling in Parkinson's disease. Nat Neurosci 18:779-786. CrossRef Medline

DeLong MR (1990) Primate models of movement disorders of basal ganglia origin. Trends Neurosci 13:281-285. CrossRef Medline

Follett KA, Weaver FM, Stern M, Hur K, Harris CL, Luo P, Marks WJ Jr, Rothlind J, Sagher O, Moy C, Pahwa R, Burchiel K, Hogarth P, Lai EC, Duda JE, Holloway K, Samii A, Horn S, Bronstein JM, Stoner G, et al. (2010) Pallidal versus subthalamic deep-brain stimulation for Parkinson's disease. N Engl J Med 362:2077-2091. CrossRef Medline

Fries P (2005) A mechanism for cognitive dynamics: neuronal communication through neuronal coherence. Trends Cogn Sci 9:474-480. CrossRef Medline

Geng X, Zhang J, Jiang Y, Ashkan K, Foltynie T, Limousin P, Zrinzo L, Green A, Aziz T, Brown P, Wang S (2017) Comparison of oscillatory activity in subthalamic nucleus in Parkinson's disease and dystonia. Neurobiol Dis 98:100-107. CrossRef Medline

Giannicola G, Marceglia S, Rossi L, Mrakic-Sposta S, Rampini P, Tamma F, Cogiamanian F, Barbieri S, Priori A (2010) The effects of levodopa and ongoing deep brain stimulation on subthalamic beta oscillations in Parkinson's disease. Exp Neurol 226:120-127. CrossRef Medline

Gillies MJ, Hyam JA, Weiss AR, Antoniades CA, Bogacz R, Fitzgerald JJ, Aziz TZ, Whittington MA, Green AL (2017) The cognitive role of the globus pallidus interna; insights from disease states. Exp Brain Res 235:14551465. CrossRef Medline

Gradinaru V, Mogri M, Thompson KR, Henderson JM, Deisseroth K (2009) Optical deconstruction of parkinsonian neural circuitry. Science 324: 354-359. CrossRef Medline

Hammond C, Bergman H, Brown P (2007) Pathological synchronization in Parkinson's disease: networks, models and treatments. Trends Neurosci 30:357-364. CrossRef Medline

Hochberg Y, Benjamini Y (1990) More powerful procedures for multiple significance testing. Stat Med 9:811-818. CrossRef Medline

Holt AB, Netoff TI (2014) Origins and suppression of oscillations in a computational model of Parkinson's disease. J Comput Neurosci 37:505-521. CrossRef Medline

Jimenez-Shahed J, Telkes I, Viswanathan A, Ince NF (2016) GPi oscillatory activity differentiates tics from the resting state, voluntary movements, and the unmedicated Parkinsonian state. Front Neurosci 10:436. CrossRef Medline

Kondylis ED, Randazzo MJ, Alhourani A, Lipski WJ, Wozny TA, Pandya Y, Ghuman AS, Turner RS, Crammond DJ, Richardson RM (2016) Movement-related dynamics of cortical oscillations in Parkinson's disease and essential tremor. Brain 139:2211-2223. CrossRef Medline

Koop MM, Andrzejewski A, Hill BC, Heit G, Bronte-Stewart HM (2006) Improvement in a quantitative measure of bradykinesia after microelectrode recording in patients with Parkinson's disease during deep brain stimulation surgery. Mov Disord 21:673-678. CrossRef Medline

Kühn AA, Kempf F, Brücke C, Gaynor Doyle L, Martinez-Torres I, Pogosyan A, Trottenberg T, Kupsch A, Schneider GH, Hariz MI, Vandenberghe W, Nuttin B, Brown P (2008) High-frequency stimulation of the subtha- 
lamic nucleus suppresses oscillatory beta activity in patients with Parkinson's disease in parallel with improvement in motor performance. J Neurosci 28:6165-6173. CrossRef Medline

Li Q, Ke Y, Chan DC, Qian ZM, Yung KK, Ko H, Arbuthnott GW, Yung WH (2012) Therapeutic deep brain stimulation in parkinsonian rats directly influences motor cortex. Neuron 76:1030-1041. CrossRef Medline

Liu X, Griffin IC, Parkin SG, Miall RC, Rowe JG, Gregory RP, Scott RB, Aziz TZ, Stein JF (2002) Involvement of the medial pallidum in focal myoclonic dystonia: a clinical and neurophysiological case study. Mov Disord 17:346-353. CrossRef Medline

López-Azcárate J, Tainta M, Rodríguez-Oroz MC, Valencia M, González R, Guridi J, Iriarte J, Obeso JA, Artieda J, Alegre M (2010) Coupling between beta and high-frequency activity in the human subthalamic nucleus may be a pathophysiological mechanism in Parkinson's disease. J Neurosci 30:6667-6677. CrossRef Medline

Malekmohammadi M, AuYong N, Ricks-Oddie J, Bordelon Y, Pouratian N (2018) Pallidal deep brain stimulation modulates excessive cortical high $\beta$ phase amplitude coupling in Parkinson disease. Brain Stimul. Advance online publication. Retrieved January 31, 2018. CrossRef Medline

Meidahl AC, Tinkhauser G, Herz DM, Cagnan H, Debarros J, Brown P (2017) Adaptive deep brain stimulation for movement disorders: the long road to clinical therapy. Mov Disord 32:810-819. CrossRef Medline

Miocinovic S, de Hemptinne C, Qasim S, Ostrem JL, Starr PA (2015) Patterns of cortical synchronization in isolated dystonia compared with parkinson disease. JAMA Neurol 72:1244-1251. CrossRef Medline

Miocinovic S, Swann NC, de Hemptinne C, Miller A, Ostrem JL, Starr PA (2018) Cortical gamma oscillations in isolated dystonia. Parkinsonism Relat Disord 49:104-105. CrossRef Medline

Odekerken VJ, van Laar T, Staal MJ, Mosch A, Hoffmann CF, Nijssen PC, Beute GN, van Vugt JP, Lenders MW, Contarino MF, Mink MS, Bour LJ, van den Munckhof P, Schmand BA, de Haan RJ, Schuurman PR, de Bie RM (2013) Subthalamic nucleus versus globus pallidus bilateral deep brain stimulation for advanced Parkinson's disease (NSTAPS study): a randomised controlled trial. Lancet Neurol 12:37-44. CrossRef Medline

Okun MS, Fernandez HH, Wu SS, Kirsch-Darrow L, Bowers D, Bova F, Suelter M, Jacobson CE 4th, Wang X, Gordon CW Jr, Zeilman P, Romrell J, Martin P, Ward H, Rodriguez RL, Foote KD (2009) Cognition and mood in Parkinson's disease in subthalamic nucleus versus globus pallidus interna deep brain stimulation: the COMPARE trial. Ann Neurol 65:586-595. CrossRef Medline

Ostrem JL, Racine CA, Glass GA, Grace JK, Volz MM, Heath SL, Starr PA (2011) Subthalamic nucleus deep brain stimulation in primary cervical dystonia. Neurology 76:870-878. CrossRef Medline

Ostrem JL, San Luciano M, Dodenhoff KA, Ziman N, Markun LC, Racine CA, de Hemptinne C, Volz MM, Heath SL, Starr PA (2017) Subthalamic nucleus deep brain stimulation in isolated dystonia: a 3-year follow-up study. Neurology 88:25-35. CrossRef Medline

Oswal A, Brown P, Litvak V (2013) Synchronized neural oscillations and the pathophysiology of Parkinson's disease. Curr Opin Neurol 26:662-670. CrossRef Medline

Priori A, Foffani G, Pesenti A, Tamma F, Bianchi AM, Pellegrini M, Locatelli M, Moxon KA, Villani RM (2004) Rhythm-specific pharmacological modulation of subthalamic activity in Parkinson's disease. Exp Neurol 189:369-379. CrossRef Medline

Qasim SE, de Hemptinne C, Swann NC, Miocinovic S, Ostrem JL, Starr PA (2016) Electrocorticography reveals beta desynchronization in the basal ganglia-cortical loop during rest tremor in Parkinson's disease. Neurobiol Dis 86:177-186. CrossRef Medline

Quinn EJ, Blumenfeld Z, Velisar A, Koop MM, Shreve LA, Trager MH, Hill BC, Kilbane C, Henderson JM, Brontë-Stewart H (2015) Beta oscillations in freely moving Parkinson's subjects are attenuated during deep brain stimulation. Mov Disord 30:1750-1758. CrossRef Medline

Ramirez-Zamora A, Ostrem JL (2018) Globus pallidus interna or subthalamic nucleus deep brain stimulation for Parkinson disease: a review. JAMA Neurol 75:367-372. CrossRef Medline

Rowland NC, De Hemptinne C, Swann NC, Qasim S, Miocinovic S, Ostrem JL, Knight RT, Starr PA (2015) Task-related activity in sensorimotor cortex in Parkinson's disease and essential tremor: changes in beta and gamma bands. Front Hum Neurosci 9:512. CrossRef Medline

Silberstein P, Kühn AA, Kupsch A, Trottenberg T, Krauss JK, Wöhrle JC,
Mazzone P, Insola A, Di Lazzaro V, Oliviero A, Aziz T, Brown P (2003) Patterning of globus pallidus local field potentials differs between Parkinson's disease and dystonia. Brain 126:2597-2608. CrossRef Medline

Starr PA (2002) Placement of deep brain stimulators into the subthalamic nucleus or globus pallidus internus: technical approach. Stereotact Funct Neurosurg 79:118-145. CrossRef Medline

Swann NC, de Hemptinne C, Aron AR, Ostrem JL, Knight RT, Starr PA (2015) Elevated synchrony in Parkinson disease detected with electroencephalography. Ann Neurol 78:742-750. CrossRef Medline

Swann NC, de Hemptinne C, Miocinovic S, Qasim S, Wang SS, Ziman N, Ostrem JL, San Luciano M, Galifianakis NB, Starr PA (2016) Gamma oscillations in the hyperkinetic state detected with chronic human brain recordings in Parkinson's disease. J Neurosci 36:6445-6458. CrossRef Medline

Swann NC, de Hemptinne C, Miocinovic S, Qasim S, Ostrem JL, Galifianakis NB, Luciano MS, Wang SS, Ziman N, Taylor R, Starr PA (2018) Chronic multisite brain recordings from a totally implantable bidirectional neural interface: experience in 5 patients with Parkinson's disease. J Neurosurg 128:605-616. CrossRef Medline

Taniguchi M, Kato A, Fujita N, Hirata M, Tanaka H, Kihara T, Ninomiya H, Hirabuki N, Nakamura H, Robinson SE, Cheyne D, Yoshimine T (2000) Movement-related desynchronization of the cerebral cortex studied with spatially filtered magnetoencephalography. Neuroimage 12:298-306. CrossRef Medline

Timmermann L, Gross J, Dirks M, Volkmann J, Freund HJ, Schnitzler A (2003) The cerebral oscillatory network of parkinsonian resting tremor. Brain 126:199-212. CrossRef Medline

Tinkhauser G, Pogosyan A, Little S, Beudel M, Herz DM, Tan H, Brown P (2017a) The modulatory effect of adaptive deep brain stimulation on beta bursts in Parkinson's disease. Brain 140:1053-1067. CrossRef Medline

Tinkhauser G, Pogosyan A, Tan H, Herz DM, Kühn AA, Brown P (2017b) Beta burst dynamics in Parkinson's disease OFF and ON dopaminergic medication. Brain 140:2968-2981. CrossRef Medline

Tort AB, Komorowski R, Eichenbaum H, Kopell N (2010) Measuring phase-amplitude coupling between neuronal oscillations of different frequencies. J Neurophysiol 104:1195-1210. CrossRef Medline

Tsiokos C, Malekmohammadi M, AuYong N, Pouratian N (2017) Pallidal low beta-low gamma phase-amplitude coupling inversely correlates with Parkinson disease symptoms. Clin Neurophysiol 128:2165-2178. CrossRef Medline

Voytek B, Knight RT (2015) Dynamic network communication as a unifying neural basis for cognition, development, aging, and disease. Biol Psychiatry 77:1089-1097. CrossRef Medline

Wang DD, de Hemptinne C, Miocinovic S, Qasim SE, Miller AM, Ostrem JL, Galifianakis NB, San Luciano M, Starr PA (2016) Subthalamic local field potentials in Parkinson's disease and isolated dystonia: an evaluation of potential biomarkers. Neurobiol Dis 89:213-222. CrossRef Medline

Weaver FM, Follett KA, Stern M, Luo P, Harris CL, Hur K, Marks WJ Jr, Rothlind J, Sagher O, Moy C, Pahwa R, Burchiel K, Hogarth P, Lai EC, Duda JE, Holloway K, Samii A, Horn S, Bronstein JM, Stoner G, et al. (2012) Randomized trial of deep brain stimulation for Parkinson disease: thirty-six-month outcomes. Neurology 79:55-65. CrossRef Medline

Weinberger M, Mahant N, Hutchison WD, Lozano AM, Moro E, Hodaie M, Lang AE, Dostrovsky JO (2006) Beta oscillatory activity in the subthalamic nucleus and its relation to dopaminergic response in Parkinson's disease. J Neurophysiol 96:3248-3256. CrossRef Medline

Weinberger M, Hutchison WD, Alavi M, Hodaie M, Lozano AM, Moro E, Dostrovsky JO (2012) Oscillatory activity in the globus pallidus internus: comparison between Parkinson's disease and dystonia. Clin Neurophysiol 123:358-368. CrossRef Medline

Wenzelburger R, Zhang BR, Pohle S, Klebe S, Lorenz D, Herzog J, Wilms H, Deuschl G, Krack P (2002) Force overflow and levodopa-induced dyskinesias in Parkinson's disease. Brain 125:871-879. Medline

Williams D, Tijssen M, Van Bruggen G, Bosch A, Insola A, Di Lazzaro V, Mazzone P, Oliviero A, Quartarone A, Speelman H, Brown P (2002) Dopamine-dependent changes in the functional connectivity between basal ganglia and cerebral cortex in humans. Brain 125:1558-1569. CrossRef Medline 